\title{
"SERVICIO DE DIOS Y PROVECHO Y SALUD DE LAS ALMAS". LA PREDICACIÓN MENDICANTE EN EL ARZOBISPADO DE SEVILLA DURANTE LA BAJA EDAD MEDIA
}

\author{
"SERVICE OF GOD AND BENEFITS OF SOUL". THE MENDICANT \\ PREDICATION IN THE ARCHBISHOPRIC OF SEVILLE AT THE END OF \\ THE MIDDLE AGES
}

José María Miura Andrades

Universidad Pablo de Olavide de Sevilla jmmiuand@upo.es

RESUMEN: Las órdenes mendicantes nacen de un afán de renovación eclesiástica que las convierte en un importante instrumento de reforma. Franciscanos y dominicos, con una formación intelectual importante, se dedicarán con competencia a la predicación y la confesión. Los predicadores, divididos en terminarios, celebridades locales y profetas itinerantes; los motivos de la predicación, en ocasiones hibridados con otros asuntos; los tiempos, litúrgicos y civiles; los lugares y los contenidos de la predicación en el arzobispado de Sevilla son ejemplo de la amplia y fecunda labor desarrollada por los mendicantes en el seno de la sociedad sevillana bajomedieval, de la que formaron parte y en la que influyeron de forma rotunda en la creación de su mentalidad.

PALABRAS ClAVES: órdenes mendicantes, predicación, predicadores, sermones, Andalucía, Baja Edad Media.

ABSTRACT: The mendicant orders were born from a desire for renewal that the Church used as an important instrument of reform. Franciscans and Dominicans, with a significant academic training, dedicated to preaching and confession. Preachers, divided into "terminarios", local celebrities and itinerant prophets; the reasons for preaching, sometimes mixed with other matters; liturgical and civil times; the locations and contents of preaching in the archbishopric of Seville are examples of the extensive and fruitful work of the mendicant within late medieval Seville society, of which they formed a part and in the creation of whose mentality they influenced in a decisive way.

KEYWORDS: mendicant orders, predication, preacher, sermons, Andalusia. Late Middle Ages. 


\section{INTRODUCCIÓN}

Las órdenes mendicantes nacen en un marco histórico, inicios del siglo XIII, del que son reflejo y muestra. En esos momentos la Iglesia tiene planteados tres grandes problemas: la burguesía, la pobreza y la herejía (fundamentalmente la albigense). Al tiempo, aportó dos grandes soluciones: el IV Concilio de Letrán (1215), más efectivo en la letra que en el espíritu que la determinaba; y las órdenes mendicantes, que aportaron ese espíritu necesario para la adaptación de la Iglesia a las nuevas realidades.

El espíritu mendicante se concreta en ${ }^{1}$ :

- El amor al pueblo y la identificación con el mismo, que se manifiesta externamente en la sustitución del Dom., abreviatura de Dominus (Señor), por el frater (Hermano), así como en la propia vivienda o vestidos, similares a los de sus coetáneos.

- El amor a la pobreza y la humildad tanto individual como colectiva, tanto interna como externa (en las construcciones, en el vestido, en el medio de transporte empleado...).

- La lucha contra la herejía, concretada en un doble aspecto: favorecer con sus actitudes una visión de la Iglesia alejada de los vicios que se le imputaban; y atacar y desmontar los argumentos heréticos a través de la formación intelectual y la predicación del verdadero mensaje a las masas populares.

Sin embargo, a pesar de que tales elementos intervinieron en la fundación de los principios de todas las órdenes mendicantes, no lo hicieron en la misma proporción, sino que variaron sus fórmulas en función de cada una de ellas. Junto a la pobreza, la predicación, como máxima expresión de la labor pastoral sobre el pueblo, quizás sea el elemento más característico de las órdenes mendicantes, hasta el extremo de que una de ellas, los dominicos, la incorporaron como definitoria de su propia orden: "Orden de los Predicadores". Por tanto, la predicación es parte constitutiva del hecho mismo de la existencia de las órdenes mendicantes y es consustancial a ellas ${ }^{2}$. Tanto San Francisco de Asís como Santo Domingo de Guzmán, los fundadores de franciscanos y dominicos, las dos grandes órdenes mendicantes, son esencialmente predicadores. El rasgo principal de la orden fundada por el santo de Asís es la pobreza y la simpatía con el pueblo. Su propio nombre "Orden de los Hermanos Menores" así lo indica. La pobreza franciscana no es sólo una pobreza material sino también y sobre todo "privación de los bienes morales: fama, prestigio, dignidad... El ideal del franciscanismo es la imitación del Cristo pobre y crucificado (humillado)" 3 . Ya desde los inicios de la orden la formación intelectual y su necesidad para la predicación se convirtió en punto de divergencia

1. En este sentido es interesante la obra de J.M. Moliner. Espiritualidad Medieval: Los Mendicantes. Burgos, 1974.

2. D.L. d'Avray, The preaching of the friars. Sermons diffused from Paris before 1300. Oxford, 1985.

3. J.M. Moliner. Espiritualidad ..., p. 50. 
en el interior de la orden creándose los sectores "celantes" y "sapientes". Por contra, la predicación, el debate con y contra los herejes y la necesaria formación intelectual para ello definen el ideal dominico. El propio Honorio III al aprobar la orden así lo hace constar "atletas de la fe y verdaderas lumbreras del mundo" al dirigirse a ellos ${ }^{5}$. Este matiz, sobre todo el de la formación intelectual, hizo que la orden tuviera un menor contacto directo con el pueblo y calara en mayor grado en las altas capas sociales. También supuso, por lo efectivo de su acción pastoral, un mayor apoyo de las instituciones encargadas de velar por la salud de las almas: reyes y obispos. Mercedarios, trinitarios, carmelitas, agustinos y mínimos se encontraban más alejados de la predicación por su origen o por el desarrollo en nuestro ámbito de estudio.

Las órdenes mendicantes tienen una serie de funciones que les son propias: la actividad apostólica o pastoral, dentro de la que tendrían cabida las actividades predicacional, misional y sacramental como elementos principales y de más directa vinculación. A través de su predicación, repleta de un importante contenido moral, provocaban mayor vitalidad en la vida espiritual de los fieles. Sus acciones, entre otras, también estaban orientadas a hacer visible la función del laicado en la comunidad eclesial, patrocinando la vida espiritual fuera de los claustros, cuya plasmación más inmediata fueron las beatas y ermitaños que acabaron confluyendo en las órdenes terciarias ${ }^{6}$.

Sin embargo, precisamente por su incardinación dentro del marco social, junto a ellas asumen funciones que en puridad no les corresponden, pero que no tienen más remedio que aceptar, al no existir mecanismos dentro de lo laico o lo civil capaces de llevarlas a cabo. Es decir, las órdenes mendicantes no son especialistas ni es objetivo de su misión el realizar tales tareas, pero las asumen e intentan realizar por ser las más capacitadas para ello, justamente por el hecho de estar preparadas para realizar las funciones que les son propias.

Si analizamos esta multiplicidad de funciones que van a jugar las órdenes mendicantes podemos diferenciar:

- las que juegan como propietarios de un recinto físico con unas cualidades jurídicas y mentales propias: los espacios conventuales.

- las que realizan como comunidad constituida con unas capacidades y la valoración de las mismas: las comunidades conventuales.

- las que asumen los diferentes miembros de las citadas comunidades: los individuos conventuales.

La claridad de las funciones correspondientes a este triplete de vectores, no está presente en la realidad de los hombres y las comunidades que los encargaban o de los que hacían dejación, sino que son el resultado de una clasificación del historiador. El ser social bajomedieval no distinguía entre las bondades del edificio,

4. Ibidem, pp. 52-55.

5. Ibídem, p. 58.

6. Puede verse la obra de J.M. Miura Andrades. Frailes, monjas y conventos. Las órdenes mendicantes y la sociedad sevillana bajomedieval. Sevilla, 1998, especialmente lo relativo a las fundaciones autogenéticas. 
de la comunidad y del individuo y, de hecho, nunca lo hicieron, sino que, al contrario, fueron adicionando las distintas funcionalidades y analizaron la resultante, que, en última instancia, era lo que les interesaba.

Es nuestra intención centrar nuestro estudio en uno de los grandes ingredientes del espíritu mendicante: la predicación, que además es una clara muestra de la labor social y religiosa realizada sobre el conjunto social y lo haremos sobre el espacio del arzobispado de Sevilla durante los siglos XIII a inicios del XVI.

Los estudios sobre la predicación durante el periodo bajomedieval se han desarrollado de manera pausada pero continua en las últimas décadas. Tanto en lo referente al ámbito europeo ${ }^{7}$ como al peninsular ${ }^{8}$. En nuestro país, el despertar del estudio sobre la predicación se encuentra en un conjunto de meritorios trabajos dentro del dominio literario y referidos, fundamentalmente, a la oratoria sagrada. Por ello el sermón, su catalogación y su edición crítica han ocupado el interés de los estudiosos sobre el tema9 ${ }^{9}$. Pedro M. Cátedra constituye, sin duda, la referencia en esta línea ${ }^{10}$. El “Ars praedicandi” ha sido objeto de estudio y atención, así como las maneras de realizar la predicación y los artilugios y recursos escénicos ${ }^{11}$. Con la predicación se imparte doctrina y contenidos pastorales que han centrado el estudio de algunos autores ${ }^{12}$. En ocasiones se ha transitado el camino del estudio de algunos predicadores ilustres o especialmente documentados. Especialmente para el ámbito Peninsular se ha centrado el estudio en la figura de San Vicente Ferrer.

7. De gran utilidad es el trabajo de C. Muessig. "Sermon, Preacher and Society in the Middle Ages", Journal of Medieval History 28 (2002), pp. 73-91, especialmente lo referido a la predicación mendicante y los estudios realizados sobre ella entre las pp. 80-86. Para el ámbito italiano A. Thompson. Revival Preachers and Politics in Thirteenth-Century Italy. The Great Devotion of 1233. Oxford, 1992.

8. M.A. Sánchez Sánchez. "Dos décadas de estudios sobre predicación en la España medieval", Erebea, Revista de Humanidades y Ciencias Sociales 1 (2011), pp. 3-20.

9. F. Rico. Predicación y literatura en la España medieval. Cádiz, 1977; A. D. Deyermond. "The Sermon and its uses in Medieval Castilian Literature", La Corónica, VIII (1979-1980), pp. 127-148; N. Salvador Miguel. "Ediciones de textos medievales, II", Medievalismo. Boletín de la Sociedad Española de Estudios Medievales, 5 (1995), pp. 263-267.J. Sánchez Herrero y A.M.C. García Martínez. "Incunables de sermones de la Biblioteca Universitaria de Sevilla. Catalogación y aproximación a su estudio", De libros y bibliotecas. Homenaje a Rocío Caracuel. Sevilla, 1995, pp. 333-352. Los autores nos hablan de más de 15.000 sermones. M.A. Sánchez Sánchez. La primitiva predicación hispánica medieval: tres estudios. Salamanca, 2000.

10. P.M. Cátedra García. Dos estudios sobre el sermón en la España medieval. Barcelona, 1981; Sermón, Sociedad y Literatura en la Edad Media. San Vicente Ferrer en Castilla (1411-1412). Salamanca, 1994; "Nuevas aportaciones al corpus de la predicación castellana medieval", Studia in Honorem Germán Orduna. Alcalá de Henares, 2001, pp. 181-194; "Últimos restos de la predicación castellana de san Vicente Ferrer", en "Pulchre, bene, recte". Estudios en homenaje al prof. Fernando González Ollé, Pamplona, 2002, pp. 285-302.

11. A.M.C. García Martínez. La escritura transformada: oralidad y cultura escrita en la predicación de los siglos XV al XVII. Huelva, 2006.

12. Es un buen ejemplo de este uso del contenido de los sermones el trabajo de J. Pérez-Embid Wamba. "Sobre el trasfondo social de la predicación mendicante en Castilla y León (siglo XIII)", Erebea. Revista de Humanidades y Ciencias Sociales 1 (2011), pp. 103-136. B. Marcotegui Barber "Instructio fidei. La enseñanza doctrinal en los sermones medievales navarros", Erebea. Revista de Humanidades y Ciencias Sociales 1 (2011), pp. 157-176. 
Sin embargo, nuestra aportación intenta cubrir la laguna de los predicadores, las motivaciones, los tiempos, los lugares y las consecuencias de la predicación.

\section{LAS MOTIVACIONES DE LA PREDICACIÓN}

La predicación y los sermones son así una de las vías utilizadas para, entre otras funciones, llevar la dirección moral y espiritual del conjunto social. Muy clara, de que esta función predicacional es consustancial a la propia existencia de las órdenes mendicantes y que la misma se había confundido y mezclado con otras funcionalidades espurias, se muestra la carta del Maestro General de la Orden de Predicadores al Capítulo de la Congregación de la Observancia celebrado en Peñafiel en 1504, por la que manda:

"Algunos conventos que tienen posesiones, desprecian enviar predicadores a los pueblos, diciendo que ellos no padecen necesidad para ejercer ese ministerio. Para remediar tan grave error, según parece a algunos que se ha de predicar no por Cristo sino para conseguir limosnas, mando con todo rigor a los presidentes de los conventos, gravando la conciencia de los mismos, que, teniendo en cuenta las necesidades de los pueblos y su posibilidad, envien predicadores en las cuaresmas $y$ en las grandes festividades, para consolar a las gentes. Y declaro que, si por tener posesiones, no quieren predicar, con mala conciencia las tienen y contra la voluntad de la Orden y contra las intenciones de la Sede Apostólica"13.

En definitiva, el predicador mendicante lo es por propia vocación, casi por razón de su propia naturaleza. Hervé Martin los ha definido como "Profesionales de la Palabra" frente a "Los Locutores Intermitentes", que serían los seculares y los religiosos tradicionales ${ }^{14}$. Ello no es óbice para que, por el desarrollo de esa labor, reciba una serie de beneficios, normalmente ayudas a su mantenimiento corporal o profesional o de aquellos que venían en su compañía, o que, incluso, el desarrollo de esa labor se convierta en su forma de ganarse la vida, pero no es el fin de la predicación sino el medio o la consecuencia de ella ${ }^{15}$.

En ocasiones se utiliza el sermón y la predicación como incentivo a la dotación de limosnas. Un caso claro de tal uso es el privilegio que se le concede en 1315 a los trinitarios. Por él se obliga a los vecinos mayores de doce años a asistir a la predicación y, en el caso de no asistir, se les multaba con diez maravedís ${ }^{16}$. El

13. Acta de los Capítulos Provinciales de la Provincia de España (ACPPE), Peñafiel, 1504. R. Hernández. "Actas de la Congregación de la Reforma de la Provincia de España (II)", Archivo Dominicano, II, 1981, pp. 19 y 102-103.

14. H. Martin. Le Métier de Prédicateur à la fin du Moyen Age. 1350-1520. París, 1988, pp. 131-189.

15. H. Martin. Le Métier..., pp. 149-165, ha analizado estos aspectos relativos a los salarios y compensaciones a los predicadores franceses.

16. Archivo Histórico Nacional (AHN), Secc. Clero. Valladolid, C. 3250, n. 17. CIT. A. Rucquoi. Valladolid en la Edad Media. El Mundo Abreviado. II. Valladolid, 1987, p. 373. 
abuso de esta medida, que mantenía a algunos vecinos hasta ocho días encerrados oyendo el sermón, llevó a las Cortes de Soria de 1380 a su anulación a los vecinos por causa de la obligación de asistencia a las predicaciones ${ }^{17}$.

El uso de la predicación con fines recaudatorios queda claro en numerosas ocasiones. Tal es el caso de fray Íñigo de Mendoza y fray Diego de Castroverde (este último fraile en 1483 de San Francisco de Jerez ${ }^{18}$ ) quienes, deseando estudiar Teología en la Universidad de Bolonia o en París, en 1476 recibieron licencia de Sixto IV para cursar estudios universitarios por cuatro años, liberándolos de la dependencia de los superiores de la orden, y los autoriza a recorrer los reinos de Castilla y León durante un año para recaudar, en limosnas, lo necesario para el mantenimiento de su periodo universitario ${ }^{19}$. Casos similares nos constan en la ciudad de Sevilla. En 1473, el concejo de Sevilla concedía a fray Miguel, fray Dionisio y fray Diego, "monjes profesos del monasterio de San Basilio de Negroponte, humildes y devotos oradores", 3000 maravedís de limosna ${ }^{20}$. En ocasiones la ciudad de Sevilla ayudó a sufragar los gastos de los estudios de diversos personajes como fray Martín, dominico licenciado en teología, en $1409^{21}$ fray Alfonso de Sanlúcar, franciscano, licenciado en Teología, en $1417^{22}$ y el "devoto padre fray Francisco", franciscano, para su magisterio en Teología ${ }^{23}$.

\section{LOS PREDICADORES}

Al ser la predicación fundamental para la labor pastoral de franciscanos y dominicos, desde los primeros tiempos demostraron un gran interés por su formación intelectual ${ }^{24}$. Era necesario hacer uso de la palabra, lo que suponía un profundo co-

17. Cortes de los Antiguos Reinos de León y Castilla. Editado por Real Academia de la Historia (RAH). Madrid, 1861-1903, tomo II, Cortes de Soria 1380.

18. 1483, septiembre, 1. Jerez. Donación de la comunidad de San Francisco de Jerez, entre los que figura fray Diego de Castroverde, a la viuda y descendientes de Juan de Vargas, del suelo para edificar una capilla en el altar mayor. EDIT. H. Sancho de Sopranis. "San Francisco el Real de Jerez en el Siglo XV", Archivo Ibero-Americano, octubre, 1945, n. 5, pp. 366-404 y 481-527, en concreto p. 523-525. En 1490 nos consta su presencia en Jerez donde actúa como prestamista. Archivo de Protocolos (AP) depositado en el Archivo Histórico Municipal de Jerez de la Frontera (AHMJF), Bartolomé de Maya, Miércoles, 5 de mayo de 1490. Fol.122r.; y Lunes, 16 de agosto de 1490. Fol.278v. Agradezco a la Dra. Pérez González la información facilitada del AP.

19. 1476, febrero, 28. J. Pou y Martí. Bullarium Franciscanum contines constitutiones, epistolas, diplomata Romani Pontificis Sixti IV, ad tres Ordines S.P.N. Francisci spectantia. Nova Serie. Tomus III (1471-1484). Quaracchi, prope Florentiam, 1949 (BFNS, III), n. 849. M.R. Pazos. "Los Franciscanos Españoles en el Pontificado de Sixto IV (1471-1484)", Archivo Ibero-Americano, tomo X, 1950, pp. 67-150, p. 100-101.

20. 1473, julio, 30. Archivo Municipal de Sevilla (AMS), Papeles del Mayordomazgo, 1474-1476 (1474) (58).

21. 1409, marzo, 29. AMS, Papeles del Mayordomazgo, año 1408, n. 102.

22. 1417, abril, 13. AMS, Papeles del Mayordomazgo, año 1416, n. 110.

23. 1493, marzo, 8. AMS, Papeles del Mayordomazgo, 1493-1494, (73).

24. J. Longere. La Prédication Médiévale. París, 1983, pp. 93-129, donde se encontrará tanto la legislación como un somero pero indicativo elenco de predicadores de las diversas órdenes. 
nocimiento del contenido y de la forma del mensaje que sólo era posible adquirir por el estudio. Los grandes predicadores suelen ser maestros en Teología.

La primera presencia de mendicantes predicando en las tierras del arzobispado hispalense se corresponde aún con la presencia del poder político musulmán sobre el territorio.

En el Capítulo de Esteras, celebrado en Pentecostés de 1219, la orden franciscana decidió, además del envío de diversos grupos de frailes por las naciones católicas con letras comendaticias del Papa, la partida de tres grupos misionales: uno hacia Oriente, presidido por Francisco; otro dirigido a Túnez, bajo la dirección de fray Gil; y un tercero que tendría como destino Marruecos. Este último grupo estaba compuesto de seis frailes: lo presidía fray Vidal, a quien acompañan fray Berardo Leopardi, conocedor del árabe; fray Pedro Cattani, Fray Otón, fray Adjuto y fray Acursio (legos estos dos últimos). Tras pasar por Aragón -donde quedó enfermo fray Vidal-y Portugal, en otoño de 1219 llegaron a Sevilla con el fin de misionar las tierras del Miramamolín de Marruecos. En Sevilla, inician su predicación y son encarcelados a la espera de recibir la pena capital. Desde sus almenas predicaban, según la tradición hagiográfica, a cuantos entraban y salían del palacio, lo que aún molestó más si cabe al poder musulmán. Sin embargo, por estas fechas la situación de Al-Andalus no era la más idónea para proceder a su ejecución pública por lo que se les trasladó a Marruecos junto con una compañía de mercenarios cristianos que se encontraba bajo las órdenes del Infante don Pedro de Portugal (hermano de Alfonso II), donde, quizás más desprotegidos por las circunstancias, fueron primero expulsados a Ceuta y, negándose a abandonar Marruecos, el 16 enero de 1220 terminaron siendo martirizados tras predicar al Miramamolín en Marraqués. Sus cuerpos fueron traslados por el infante don Pedro a Portugal donde recibieron culto en Coimbra, en Santa Cruz, abadía de canónigos regulares donde se encontraba San Antonio de Padua, despertándosele, entonces, su vocación franciscana ${ }^{25}$.

Para el siglo XV y los inicios de la decimosexta centuria contamos con datos más concluyentes. Conocemos un considerable número de predicadores mendicantes, lo cual no indica que otros personajes no realizaran tal ministerio. No es nuestra intención realizar un elenco completo de los predicadores mendicantes que actuaron en el arzobispado de Sevilla, de los que aportamos información detallada de dieciocho de ellos, sino tan sólo trazar una aproximación a la variedad de los mismos, tanto en lo referido a órdenes como en lo que se relaciona con su formación. La relación, para cuya realización nos hemos basado, fundamentalmente, en las menciones de pago que hemos encontrado en los Papeles del Mayordomazgo de Sevilla y las Actas Capitulares de Écija, se completa con referencias

D.L. d'Avray. The preaching..., pone el acento en la formación universitaria de los predicadores mendicantes.

25. El acontecimiento y los pormenores de la misión se encuentran en el relato hagiográfico Passio Sanctorum Martyrum fratrum Beraldi, Petri, Adiusti, Accursii, Othonis in Marochio Martyrizatorum. Analecta Franciscana, III, Ad Claras Aquas, Roma, 1897. 
encontradas en otras fuentes no estudiadas de forma seriada y utilizadas como complemento.

Así contamos con los diferentes tipos de predicadores que Hervé Martín determina en su catalogación ${ }^{26}$ : terminarios, celebridades locales y profetas itinerantes.

Los terminarios ejercían su apostolado en los términos del convento. Normalmente se trata de hombres modestos pero trabajadores, con una labor bastante oscura. Consideramos que los son:

- Fray Juan de la Cal de Armas, del que tan sólo sabemos que aparece en una escritura de inicios del siglo XV en el convento de San Pablo de Sevilla, del que apostilla el autor del Catálogo de los priores de San Pablo "que parecer el mismo que disputó con el hereje y lo convenció" ${ }^{27}$.

- Fray Alfonso, doctor, religioso dominico de San Pablo, que predicó la cuaresma de 1425 en Morón de la Frontera, recibiendo en enero del año siguiente 150 maravedís del mayordomo del concejo de Morón ${ }^{28}$.

- Fray Manuel, de la orden de San Francisco, quien en 1427 predicaba en Sevilla, recibiendo, del concejo de ella, 1000 maravedís para comprar el libro de Nicolao de Lyra para preparar los sermones ${ }^{29}$.

- Fray Francisco, de la orden de los menores, quien antes de 1430 predicaba en Sevilla, resultado de lo cual el concejo acordó dar en limosna a su convento 2000 maravedís en dicha fecha ${ }^{30}$.

- Fray Pedro de Almansa, agustino. Este predicador nos es muy bien conocido, aunque creemos que su importancia es menor que la documentación que de él se nos ha conservado. Nuestro conocimiento del personaje parte de un pleito entre el cabildo catedral y el citado fraile. El Prof. González Jiménez publicaba el contenido de un sermón que se conservaba, en extracto y por declaraciones, en el archivo de la catedral de Sevilla ${ }^{31}$. Al dorso del mismo se extractaba como "información que se tomó en Alcalá de Guadaira contra vn fraile agustino que predicando dixo çiertas palabras injuriosas y en perjuizio de los clérigos", pero no aparecía datado con el año, tan sólo con el día de la semana, día del mes, y mes. El autor de la transcripción

26. H. Martin. Le Métier..., p. 170-182.

27. 1404, abril, 25. Sevilla. Es uno de los signantes de la escritura del traslado de los huesos del arzobispo de Santiago don Fr. Berenguel de Landoza, XIII Maestro General de la Orden. J. Herrera. Cathálogo de los Priores de el Real Convento de San Pablo de Sevilla i de los Sucesos más Notables que Acontecieron en su Tiempo. Ms. depositado en el Archivo General de la Orden de Predicadores (AGOP), Santa Sabina, Roma. Secc. XI, doc. n. 12460, n. 5, (en adelante Catálogo...), p. 25, nota marginal y p. 48 , nota marginal.

28. 1426, enero, 8. Morón. Cuenta que recibió el concejo y hombres buenos de la villa de Morón de Sancho García, mayordomo de dicho concejo, por la que consta que dio "a frey Alfonso, doctor de Sant Pablo, porque siruió aquí la Quaresma, çiento e çincuenta maravedís”. Archivo Municipal de Morón de la Frontera (AMMF), Actas Capitulares, f. 98 r. EDIT. M. González Jiménez; y M. García Fernández (Eds.). Actas Capitulares de Morón de la Frontera (1402-1426). Sevilla, 1992, p. 134.

29. 1427, octubre, 1. AMS, Papeles del Mayordomazgo, año 1427, n. 29.

30. 1430, septiembre, 1. AMS, Papeles del Mayordomazgo, año 1430-1431, n. 28.

31. Archivo Catedral de Sevilla (ACS), sin catalogar. EDIT. M. González Jiménez. "Nivel Moral del Clero Sevillano a fines del s. XIV”,Archivo Hispalense, n. 183, 1977, pp. 199-204. 
lo dejó con una fecha referencial de fines del siglo XIV (1370-1400). El documento era el resultado de las denuncias formuladas por Antón Martínez, vicario de Alcalá de Guadaíra, y otros contra fray Pedro del convento de San Agustín de Sevilla, quien había predicado en la iglesia de San Miguel de Alcalá el domingo cuatro de enero, por razón de la misa nueva que cantara Antón Sánchez, sacristán en dicha iglesia. El documento es uno de los pocos testimonios que tenemos del contenido de las predicaciones en el arzobispado de Sevilla.

Por otro lado, el cinco de julio de 1437 el corregidor informaba a los oficiales del concejo de Sevilla cómo la iglesia de esta ciudad escribió al rey sobre las arengas que pronunciaba fray Pedro de Almansa. El rey encargó que fray Pedro, dominico en San Pablo de Sevilla, hiciera pesquisas y se las remitiese junto con el fraile, por lo que el corregidor pedía al concejo los maravedís necesarios para la ida a la corte de los frailes y los aguaciles que habían de acompañarlos ${ }^{32}$. La carta posiblemente sea de la que se da traslado y que fue leída en cabildo de Sevilla cuyo contenido es

“...et en rasón de lo que tane a los frayles de San Agostín yo vos enbio mi carta para frey Esteuan, prinçipal de la dicha orden de San Agostín, que venga luego a mí fasédgela luego notificar et enbiadme luego la letura della por que yo prouea sobre todo como cunpla a mi seruiçio. De Madrid a primero de junio de treynta e seys. Otrosí yo vos enbié mi carta para los prouisores e vicarios de Seuilla sobre el ynsulto de los freyes de San Agostín, fasedgelo luelgo dar. Relator" ${ }^{\prime 3}$.

Tenemos por tanto en 1437 un pleito de la Iglesia de Sevilla contra un tal fray Pedro de Almansa y un insulto de los frailes de San Agustín. Retomando el documento sin data custodiado en la Catedral sevillana deducimos de todo ello que los tres documentos se refieren al mismo hecho, que así podemos datar en $1437^{34}$.

- Fray Miguel, franciscano, maestro en Teología, residente en San Francisco el Real de Jerez, quien predicó el 16 de abril de 1484 en El Puerto de Santa María ${ }^{35}$.

- Fray Pascual, dominico, maestro en Teología, que predicaba en Écija, por lo que los oficiales del concejo pidieron al Vicevicario de la Observancia que no lo trasladara a Jaén ${ }^{36}$. No tenemos otro dato pues las actas de los Capítulos Provinciales no hacen referencia a ningún fray Pascual asignado a Jaén entre 1493 y 1495, ni a Écija con anterioridad.

32. 1437, julio, 5. AMS, Actas Capitulares, 1437, julio, 5. 29, fol. 29. REG. N. Palenzuela Domínguez. Las Actas Capitulares del Concejo de Sevilla (1435-1447). Memoria de licenciatura inédita, Sevilla, 1986.

33. 1437, junio, 14. AMS, Papeles de Mayordomazgo, 1436-1437. Pedido, 1436.

34. En 1437 el día cuatro de enero coincidió en domingo, tal y como recogía el pleito del que nos daba noticia el Prof. González Jiménez.

35. 1484, abril, 16. H. Sancho de Sopranis. "San Francisco...”, pp. 526-527.

36. 1494, abril, 30. Écija. Archivo Municipal de Écija (AMEc), Actas Capitulares, Leg. 1, f. $338 v$. 
- Fray Diego Méndez, franciscano. Guardián del convento de San Antonio de Écija. Predicó los sermones del día de la Candelaria y en la procesión que se hizo a Nuestra Señora del Valle el día del alumbramiento de la princesa en 1503, por lo que recibió 400 maravedís ${ }^{37}$.

- Fray Juan de Pro, dominico, quien recibió en 1503, de parte del concejo de Écija, 100 maravedís por predicar en las alegrías del nacimiento del príncipe $^{38}$.

- Fray Martín de Ullate, religioso agustino. A fines de 1505 predicó a los moriscos del Reino de Granada y después a los de Sevilla, que habían quedado en el Adarbejo, y logró la conversión de los mismos, logrando el bautismo de numerosos musulmanes, por lo que prácticamente desaparecieron los mismos de Sevilla ${ }^{39}$.

- Fray Bernardino, religioso de San Agustín de Sevilla. Fadrique Enríquez de Ribera, primer marqués de Tarifa, pide al General agustino que, por ser predicador, lo destine y no lo traslade del convento sevillano, lo que el General concede en $1512^{40}$.

A las celebridades locales se les encargaban la realización de los sermones de los grandes momentos o de las grandes celebraciones. Nos son bien conocidos por mantener una estrecha relación con las instituciones urbanas.

- Fray Juan Rapado, mercedario. Fue comendador de La Merced de Jerez, desde al menos 1410, en que aparece con tal cargo en sus actas capitulares. Debió de encontrarse al servicio del Infante don Fernando o conocerle durante su estancia andaluza relacionada con la campaña de Antequera, puesto que las menciones que del mismo hay en las actas jerezanas hacen referencia una y otra vez al Infante, ya sea para pedir por su triunfo sobre los moros con rogativas y procesiones, lo que le supuso el pago de 500 maravedís por su servicio por parte del cabildo xericense $\mathrm{e}^{41}$, ya por su ac-

37. 1503, marzo, 16. Écija. Archivo Municipal de Écija (AMEc), Actas Capitulares, Leg. 2, c. 204, 31. En 1504 volvió a predicar en la fiesta de la Candelaria y también el día de la victoria de Saelices volviendo a recibir 200 maravedís por sermón. 1504, abril, 19. Écija. AMEc, Actas Capitulares, Leg. 2, c. 208,36 .

38. 1503, abril, 24. Écija. AMEc, Actas Capitulares, Leg. 2, c. 205, 7. En 1506 seguía asignado al convento de Écija (ACPPE, Burgos, 1506. EDIT. R. Hernández. "Actas de los Capítulos Provinciales de la Provincia de España (I)", Archivo Dominicano, III, 1982, pp. 13-84, p. 73. En 1510 era prior en Écija, año en el que propuso al cabildo el cambio de unas casas y calle para mejorar el convento y el paso de la procesión del Corpus Christi (1510, julio, 15. Écija. AMEc, Actas Capitulares, Leg. 2, c. 216, 2).

39. D. Ortiz de Zúñiga. Anales Eclesiásticos y Seculares de la Muy Noble y Muy Leal Ciudad de Sevilla.... Reproducción fotoestática de la reimpresión de 1795, Sevilla, Guadalquivir ediciones, 1988, t. III, p. 204.

40. 1512, septiembre, 23. Archivo General de la Orden de San Agustín (AGOSA), Regestos Generalicios, sign. Dd 11, fol. 87v. CIT. I. Aramburu Cedoya. "La Provincia de Castilla en los años 1505-1525. Notas Complementarias",Archivo Agustiniano, Vol. LIX, n. 175, 1965, pp. 5-48, p. 33.

41. 1410, junio, 30. Jerez de la Frontera. "Mandaron dar mandamiento para Bartolomé Sánchez de Écija, mayordomo del concejo, que de los proprios e rentas del dicho concejo de ende, en este segundo tercio, a frey Johan Rapado, comendador del monasterio de la orden de Santa María de la Merced desta cibdad, quinientos maravedís... por quanto el dicho comendador, por seruicio de Dios e 
tuación como predicador por ese mismo tiempo, lo que supone el reconocimiento de las exenciones al bacinador de la Merced, Esteban Fernández Palomino, vecino en el arrabal de $\operatorname{Santiago}^{42}$ y, tan sólo unos meses más tarde, presentando, junto con el prior de San Francisco y Santo Domingo, en el cabildo jerezano una carta del Infante ${ }^{43}$.

- Fray Miguel Rapado, obispo de Grossopoli, del que desconocemos su filiación religiosa, al que encontramos predicando en Sevilla, posiblemente la cuaresma, en marzo de $1442^{44}$.

- Fray Alonso de Espina, dominico, del que nos dice Ortiz de Zúñiga que fue "docto y religioso". Predicó la Cruzada en Sevilla, por designio de Enrique IV, en 1457, obteniendo grandes $\operatorname{logros}^{45}$. Debe tratarse de fray Alfonso del Spino, lector en Teología, perteneciente al convento de Santo Domingo de Jerez, a quien, en 1427, el papa Martín V autoriza a vivir en el eremitorio de Santa Catalina del Río, en la diócesis de Sevilla, con un socio idóneo "pro contemplativa et laudabiliori vita per eum pro salute anime sue"46. En 1434 el Capítulo Provincial de la Reforma asignaba al convento de Jerez a Fr. Antonium de Spino pro Doctore ${ }^{47}$. Creemos que se trata del mismo personaje Antonio o Alfonso del Spino, quien seguía en Santo Domingo de Jerez ocho años después de la concesión de su retiro en Santa Catalina del Río. Por los datos que tenemos podemos situar a esta ermita en la vega del río Guadalete $^{48}$.

- Fray Antonio de Alcalá, franciscano. Es, sin lugar a dudas, el gran predicador de la ciudad de Sevilla de la segunda mitad del siglo XV. En 1457

de nuestro sennor e del noble sennor infante don Ferrando, en las prosesiones e rrogacyones que se an fecho en esta cibdad e se an de fazer [¿pide?] porque Dios nuestro sennor e la Uirgen Sancta María con toda la corte del cielo les quiera dar vencimyento e vitoria contra los moros enemigos de la Sancta Fee Cathólica". Actas Capitulares, fol. 96 del cuaderno original, 194 de la transcripción de A. Muñoz. Los Fechos de Cabildo, / (Memorias Xerezanas del Siglo XV) / Transcripción / Paleográfica de las Actas Capitulares / de 1409 a 1498 / custodiadas en el Archivo Municipal / de la M.N. y M.L. Ciudad / de / Xerez de la Frontera / por Agustín Muñoz y Gómez, / Oficial Archivero / del Excmo. Ayuntamiento de la misma / Tomo $1^{\circ}$ / Años de 1409 y 1410. / Año de 1889, AHMJF, XIII-IV-42. EDIT. H. Sancho de Sopranis. Mariología Medieval Xericense. Jerez de la Frontera, 1973, p. 26 y 43.

42. 1410, junio, 30. Jerez de la Frontera. Actas Capitulares, fol. 97v. del cuaderno original, 196-197 de la transcripción de A. Muñoz. Los fechos... EDIT. H. Sancho de Sopranis. Mariología..., pp. 26-27 y $42-43$.

43. 1410, julio, 13. AHMJF, Acta Capitular, libro capitular, fol. 67. EDIT. H. Sancho de Sopranis. "San Francisco...".

44. 1442, marzo, 28.AMS, Papeles del Mayordomazgo, 1438-1441.

45. D. Ortiz de Zúñiga. Anales..., t. III, p. 12.

46. 1427, marzo, 20. H. Mainardi, (Ed.). Bullarium Ordine Praedicatorum (BOP). Roma 17301740 , t. II, 676 .

47. EDIT. R. Hernández. "La Reforma Dominicana entre los Concilios de Constanza y Basilea", Arquivo Histórico Dominicano Portugués, Actas do III Encontro sobre História Dominicana. Porto, 1989, vol. IV/2, pp. 151-179.

48. Agradezco esta información al Dr. Mingorance Ruiz quien gentilmente me ha facilitado las referencias. AHMJF, Actas Capitulares, fo 58r., 11 de diciembre de 1447: Camino de Santa Catalina. $F^{o}$ 26r., 10 de diciembre de 1498: Vega de Santa Catalina. F ${ }^{\circ} 119$ rv., 5 de febrero de 1535: Camino ermita Santa Catalina. 
Calixto III lo nombra obispo de Ampurias en Cerdeña ${ }^{49}$, al cual Pío II le admite la renuncia al obispado y le asigna una pensión de 50 florines de oro cobrados en Barcelona al año siguiente ${ }^{50}$, y lo autoriza a ejercer funciones pontificales con autoridad de los ordinarios que se lo pidan ${ }^{51}$. Unos meses más tarde lo encontramos en Sevilla, de la que recibe 1000 maravedís para su ayuda, bien por los sermones que había predicado o con la promesa de realizar la predicación ${ }^{52}$. Vuelve a recibir otros 5000 maravedís tan sólo seis meses más tarde, constando tan sólo que es para ayuda a su mantenimiento $^{53}$. Medio año más tarde recibe aún una cantidad mayor, 10000 maravedís, pero ahora sí nos consta que lo es "por el trabajo que se tomaba en predicar la palabra de Dios" ${ }^{54}$. En 1461 recibe la misma cantidad pero se le denomina no ayuda sino salario porque está haciendo "muchos y muy devotos sermones" ${ }^{55}$, y otros 5000 en $1462^{56}$. Nos consta que participó activamente en los acontecimientos religiosos y políticos de la Castilla de su tiempo. Palencia dice de él "El Obispo de Ampurias, fray Antonio de Alcalá, franciscano, ilustre profesor de Teología y reputado entre los españoles por hombre de vasta instrucción... ... hombre de gran instrucción pero de carácter tímido" 57 y lo sitúa predicando en Sevilla tratando de tranquilizar al pueblo tras un ciclón ${ }^{58}$. Cuando Francisco de Toledo, en sus sermones reprobó la deposición de Enrique IV de Castilla "fue respondido e probado lo contrario por don Antonio de Alcalá, obispo de Asturias (sic), frayle de la orden de San Francisco, varón muy notable e de gran ciencia" "59, lo que encaja perfectamente con su estancia sevillana claramente decantada desde el inicio del bando del infante-rey Alfonso XII ${ }^{60}$.

No nos consta otro dato de su labor predicadora en Sevilla, pero en ella debió de permanecer hasta su muerte hacia 1474. En dicha fecha, Sixto IV concede a fray García de Quesada todos los bienes del difunto fray Antonio de Alcalá, Obispo Othanense, maestro en teología, por la que nos consta que tenía una casa en Sevilla que había comprado con algún dinero que había reunido predicando ${ }^{61}$.

49. 1457, mayo, 16. BFNS, II, n. 308. A. López. "El Franciscanismo en España durante los Pontificados de Calixto III, Pío II y Paulo III a la luz de los Documentos Vaticanos”, Archivo Ibero-Americano, 3, 1943, pp. 496-570, p. 560.

50. 1458, octubre, 9. BFNS II, n. 509. REG. A. López. "El Franciscanismo..., p. 560.

51. 1458, octubre, 24. A. López. "El Franciscanismo, p. 560.

52. 1459, enero, 23. AMS, Papeles del Mayordomazgo, 1458-1459 (52).

53. 1459, julio, 16. AMS, Papeles del Mayordomazgo, 1458-1459 (52).

54. 1460, enero, 23. AMS, Papeles del Mayordomazgo, 1458-1459 (52).

55. 1461, febrero, 20. AMS, Papeles del Mayordomazgo, 1460-1465 (1461-1462) (53).

56. 1462, marzo, 24. AMS, Papeles del Mayordomazgo, 1460-1465 (1461-1462) (53).

57. A. Palencia. Crónica de Enrique IV. Madrid, 1904, t. I, p. 534.

58. Ibidem., p. 390-391

59. D. Valera. Memorial de Diversas Hazañas. Biblioteca de Autores Españoles, t. XX, p. 38, cap. XXXIV.

60. M.A. Ladero Quesada. Andalucía en el Siglo XV. Estudios de Historia Política. Madrid,1973, p. 116.

61. 1474, octubre, 6. BFNS III, n. 639. M.R. Pazos. Los Franciscanos..., pp. 102 y 142. 
- Fray Francisco, dominico, a quien propone fray Pedro de Córdoba, prior de Santo Domingo de Écija, como sustituto de fray Pascual en la predicación, por lo que los capitulares astigitanos mandaron librar 3000 maravedís para un hábito y un asno para que venga pues estaba "su persona debilitada para venir a esta ciudad a frutificar en ella con sus sermones" ${ }^{\prime 2}$. Pudiera ser el fray Francisco que en las Actas de los Capítulos Provinciales aparece asignado en 1493 a Portaceli ${ }^{63}$.

- Fray Alejo, dominico. Predicó el día de San Marcos de 1501 en la fiesta y voto que hacía la ciudad de Écija, por lo que se le libraron a los frailes de Écija un carnero y dos arrobas de vino ${ }^{64}$. Debe de tratarse del maestro fray Alejo de Peñafiel, quien aparece en las Actas Capitulares asignado al convento de Santo Domingo de Jerez como regente del estudio en $1489^{65}$. En 1493 aparece como profesor en Teología y prior de San Pablo de Sevi$11 a^{66}$, donde en 1494 aparece realizando diversos negocios ${ }^{67}$. De nuevo en 1495 se encuentra, como subprior, en el convento de Santo Domingo de $\mathrm{Jerez}^{68}$. En 1500 aparece como subprior de Jerez y Profesor en Teología, entre otras responsabilidades ${ }^{69}$. En 1502 está asignado al convento de San Pablo de Sevilla como regente de su estudio ${ }^{70}$, donde aún continuaba en $1506^{71}$ y lo seguía haciendo, como regente del estudio, en $1509^{72}$ y en $1511^{73}$.

Los profetas itinerantes, que abarcarían el periodo de la primera mitad del siglo XV, para más adelante, aún con las mismas características, centrarse en el tema de la Reforma y abarcar la segunda mitad del siglo y los años iniciales del siguiente, pero a los que ya se les denomina misioneros reformadores. Se oponen a los anteriores en su concepción de la tarea predicacional, puesto que no se establecen en un único lugar sino que tienden a desplazarse por ámbitos espaciales muy amplios, cambiando continuamente de emplazamiento.Tal es el caso de fray Álvaro de Córdoba.

- Fray Álvaro de Córdoba, dominico. Es el San Álvaro de Córdoba, canonizado popularmente, o el fray Álvaro de Zamora, pues ése debió de ser su

62. 1494, julio, 30. Écija. Archivo Municipal de Écija (AMEc), Actas Capitulares, Leg. 1, f. $351 \mathrm{r}$.

63. ACPPE, 1493. EDIT. R. Hernández. Op. cit, AD, I, p. 82.

64. 1501, mayo, 12. Écija. AMEc, Actas Capitulares, Leg. 2, c. 202, 5.

65. ACPPE, Salamanca, 1489. EDIT. R. Hernández. Op.Cit., AD, I, p. 43.

66. ACPPE, Toro, 1493. Ibidem, p. 71.

67. 1494, octubre, 6. REG. Catálogo..., p. 96, nota marginal.

68. ACPPE, Piedrahita, 1495. EDIT. R. Hernández. Op.Cit., AD, I, pp. 102 y 110.

69. ACPPE, Toledo, 1500. EDIT. R. Hernández. “Actas de la Congregación...”, pp. 36 y 44.

70. ACPPE, Jerez, 1502. EDIT. Ibidem, p. 77.

71. ACPPE, Burgos, 1506. EDIT. R. Hernández.“Actas de los Capítulos...”, p. 65.

72. ACPPE, Valladolid, 1509. EDIT. R. Hernández."Actas de los Capítulos Provinciales de la Provincia de España del siglo XVI (II)”. En Archivo Dominicano, 1986, t. VII, pp. 5-47, p. 41.

73. ACPPE, Sevilla, 1511. EDIT. R. Hernández."Actas de los Capítulos Provinciales de la Provincia de España del siglo XVI (III)”. En Archivo Dominicano, 1988, t. IX, pp. 5-53, p. 46. 
lugar de origen ${ }^{74}$. Fue profesor de teología en el Estudio General de San Pablo de Valladolid, en 1416 obtuvo el magisterio en Teología concedido por Benedicto XIII ${ }^{75}$, confesor de Catalina de Lancáster y Juan II al menos entre 1416 y 1418 , y viajero a Tierra Santa un año más tarde ${ }^{76}$. El día 21 de octubre de 1419 aparece documentalmente por primera vez en Sevilla, permaneciendo en la ciudad hasta el 13 de abril del año siguiente ${ }^{77}$. Vuelve a la ciudad de Sevilla el día 23 de diciembre de 1420 y no se marchó de ella hasta el 2 de junio de $1421^{78}$. Parece ser que cuando estaba en Sevilla se alojaba en una ermita con advocación a Santo Domingo de Porta Coeli. Al menos es lo que nos indica fray Rodrigo de Valencia fundador de Santo Domingo de Portaceli en la ciudad de Sevilla. Así, en agosto de 1440, fray Rodrigo pide al Pontífice permiso para vivir con algunos religiosos en la casa de Santo Domingo de Portaceli, que "fundó y edificó hace algunos años en Sevilla"..."donde moraba frecuentemente con sus compañeros" fray Álvaro de Córdoba ${ }^{79}$. La primera de las afirmaciones es que la fundación de una "domus cum capella seu oratio sub vocabulo Sancti Dominici de Portaceli" la realiza fray Álvaro de Zamora, donde "cum socio seu sociis moram saepe trahebat". La presencia de Álvaro de Córdoba en Sevilla nos consta pero de la misma no se deduce que erigiera el convento, tan sólo la casa con su capilla u oratorio.

En junio de 1423 fray Álvaro se encuentra en Córdoba enfrascado en su fundación de Escalaceli ${ }^{80}$, con la que colaborará un año más tarde el concejo de Sevilla con 3000 maravedís $^{81}$. En enero de 1426 se encontraba en Córdoba, donde le llevó un correo una carta el día 23 de parte del concejo de Sevilla ${ }^{82}$, posiblemente para

74. Como línea básica para el conocimiento de la biografía de San Álvaro A. Huerga. Escalaceli. Madrid, 1981, donde entre las páginas 63 y 171 se pueden espigar los datos biográficos del beato cordobés, y entre la 593 y 601, los documentos que los avalan.

75. 1416, diciembre, 21. Peñíscola. Archivo Secreto Vaticano (ASV), Reg. Avignon, t. 349, f. 347r. EDIT. A. Huerga. Escalaceli, p. 593.

76. Ibidem., pp. 87-89.

77. Cuenta que dio el mayordomo de lo que gastó en el mantenimiento del maestro fray Álvaro en el tiempo que predicó en Sevilla, desde sábado 21 de octubre de 1419 hasta sábado 13 de abril de 1420, que sumó en total 6192 maravedís. AMS, Papeles del Mayordomazgo, año 1419, n. 98.

78. El mayordomo dio "para el mantenimiento del maestro fray Álvaro que vino a predicar a esta ciudad en 23 de diciembre, marchándose de ella en 2 de junio de 1421, que fueron 160 días, a razón de 35 maravedís diarios, más 200 maravedís a su partida, 5800 maravedís". AMS, Papeles del Mayordomazgo, año 1420, n. 68-XXI.

79. ASV, Reg. Suppl. tomo 366, ff. 169v-170r. EDIT. HUERGA, A. Escalaceli, pp. 602-603.

80. 1423, junio, 13. Córdoba. Compra de la heredad de la Torre Berlanga por fray Álvaro. EDIT. A. Huerga. Escalaceli, pp. 596-597.

81. 1424, junio, 26. Mandamiento de Sevilla al mayordomo para que diese 3000 maravedís a fray Álvaro, maestro en Teología de la orden de Santo Domingo de los predicadores, para ayudar a la edificación de un monasterio de la dicha orden de la advocación de Santo Domingo de Scala Coeli, en Córdoba, en atención a los muchos y continuos trabajos que el dicho maestro se tomó en Sevilla en sus sermones. AMS, Papeles del Mayordomazgo, año 1424, n. 17.

82. Relación de lo que el mayordomo pagó a troteros y otras personas por distintos motivos por albalaes de Alfonso López, lugarteniente del escribano mayor del Concejo: ... ... por albalá de Alfonso López, de 23 de enero de 1426, dio 80 maravedís a un hombre que llevó una carta de Sevilla a fray 
que predicase la cuaresma en esta ciudad, donde lo encontramos en febrero de 1426 con tal fin ${ }^{83}$, y permanecía en marzo de dicho año ${ }^{84}$. En enero de 1427 Martín V lo nombra superior mayor de la Reforma, residente en la casa de Córdoba ${ }^{85}$. De Córdoba se trasladó fray Álvaro a Zaragoza donde lo encontramos alojado en el convento de los dominicos desde el 8 de mayo al 27 de junio ${ }^{86}$. Es la última noticia que nos consta del predicador zamorano.

Existe una larga y piadosa tradición que quiere que San Vicente estuviera en tierra andaluza. Baeza, en su catedral, conserva una cruz de San Vicente. Sevilla conserva un púlpito donde predicó el santo en el Patio de los Naranjos. Dentro de esa misma tradición andaluza se encuentra la presencia del santo valenciano en Écija. El fundamento de tal afirmación se encuentra en la existencia de un relato sobre un milagro que realizó el santo valenciano en Écija en $1414^{87}$. En torno a la figura de Vicente Ferrer se sustancian dos grandes asuntos, vinculados estrechamente entre sí: la pretensión apocalíptica (el tema del Anticristo) y la exclusión de las minorías, en particular de los judíos ${ }^{88}$. A pesar de que el tema del milagro es un proceso de conversión de una judía, es prácticamente imposible su presencia en Écija en esas fechas ${ }^{89}$ o en 1408 como quieren otros autores ${ }^{90}$. Lo cierto es que si analizamos el itinerario del santo, el propio viaje a Andalucía parece más que difícil ${ }^{91}$.

Álvaro, maestro de teología, que estaba en Córdoba. AMS, Papeles del Mayordomazgo, año 1425, n. 83-XIII.

83. 1426, febrero, 11. Albalá de Alfonso López, lugarteniente del escribano mayor del Concejo, haciendo saber al mayordomo que, en cabildo celebrado el día de la fecha, Sevilla le mandó que diese a fray Álvaro 1000 maravedís para su mantenimiento durante el tiempo que estuviese en esta ciudad predicando la cuaresma. AMS, Papeles del Mayordomazgo, año 1425, n. 37.

84. 1426, marzo, 10. Mandamiento de Sevilla al mayordomo para que diese a fray Álvaro para su mantenimiento y el de los que consigo traía durante los días que estuviese predicando en esta ciudad a los cristianos y demás vecinos y moradores, 1000 maravedís además de los otros 1000 que primeramente le mandó dar, de los que los reyes mandaban dar por sus ordenamientos a esta ciudad en limosna. AMS, Papeles del Mayordomazgo, año 1426, n. 69.

85. 1427, enero, 4. Roma. BOP, t. II, p. 694. EDIT. A. Huerga. Escalaceli, pp. 597-599.

86. Libro de gastos del convento de Zaragoza, donde en la primera fecha consta que ese día vino al convento Fray Álvaro, y en la otra que cesó en su estancia. CIT. Catálogo..., p. 30, nota marginal.

87. M. Roa. Écija, sus Santos, su Antigüedad Eclesiástica i Seglar. Sevilla, 1629. Reedición de 1890., p. 279-280. También lo cita T. Merita y Llacer. Vida, milagros y doctrina del valenciano apóstol de Europa San Vicente Ferrer. Valencia, Salvador Faulí, 1798.

88. Sobre Vicente Ferrer, además de los estudios de Pedro M. Cátedra y Antonio M.C. García Martínez, véase M.L. Martínez Carrillo, "La crisis judaica de 1411. Aportaciones a la predicación murciana de San Vicente Ferrer", Scripta. Estudios en homenaje a Élida Garcia García, Oviedo, vol. 1, 1998, pp. 343-365.

89. J.M. Miura Andrades. "Hechos extraordinarios y maravillosos en la Écija de fines de la Edad Media", Actas de las XI Jornadas de Protección del Patrimonio Histórico de Écija. "Acontecimientos naturales y sobrenaturales en la ciudad de Écija", Martín Pradas, Antonio y Carrasco Gómez, Inmaculada (Dirs.). Écija, 2014, pp. 15-32.

90. A.M.C García Martínez. "El acoso a las comunidades judías en los milagros bajomedievales", La Península Ibérica en la Era de los Descubrimientos (1391-1492).Sevilla, 1997, vol. I, pp. 301-319.

91. Sabemos que el santo se encuentra en enero de 1414 en Palma de Mallorca y parte hacia la Península. A fines de enero participa en Tortosa en las conferencias para la conversión de los judíos. 
Con la documentación que hemos manejado nos es imposible determinar en qué medida las diversas instituciones primaron más a los religiosos de unas u otras órdenes. Sin embargo, al igual que se afirma para otros ámbitos territoriales, la preeminencia de unas órdenes sobre otras a la hora de elegir a los predicadores depende, en alto grado, de la implantación territorial de las diversas comunida$\operatorname{des}^{92}$, lo que se ratifica en nuestro ámbito para el caso de Écija, repartiéndose entre dominicos y franciscanos las predicaciones de los votos del concejo ${ }^{93}$.

La mayor parte de nuestros predicadores se encuentran en posesión del Magisterio en Teología, lo cual indica la alta preparación de los predicadores en estos ámbitos, cosa, por otro lado, en la que hacía hincapié el Maestro General dominico en $1504^{94}$.

\section{LOS LUGARES DE PREDICACIÓN}

La actuación de las órdenes mendicantes es esencialmente urbana y aparece vinculada a la ciudad. Este papel se refuerza aún más para el caso de una Andalucía donde las ciudades se convierten en los centros rectores de las actividades. Dentro de la ciudad cualquier espacio podía servir para realizar la predicación, siendo preferida la iglesia y la plaza para ello, aunque, cuando la admiración levantada por el predicador era enorme se recurriera a la habilitación de grandes espacios destinados a dar cabida a acontecimientos de masas.

Sin embargo, a pesar de que la predicación sea una tarea fundamentalmente urbana, puesto que el nacimiento y el establecimiento de las órdenes mendicantes coinciden con una valoración del medio urbano, tanto en su aspecto cuantitativo para las actuaciones pastorales (centrándose el esfuerzo allí donde, por definición, había más fieles); como cualitativo (donde, por definición, había más posibilidades de pecar); ello no niega la existencia de una predicación dirigida a los ámbitos rurales. De hecho, cada convento establecido en un medio urbano, delimita un ámbito de influencia donde ejerce su acción pastoral ${ }^{95}$, incluso desde los primeros

En mayo está en Tamarit, en junio en Daroca, hasta la epifanía de 1415. Tras evangelizar Aragón, ya no volverá más a la Península. Por ello, a no ser que tuviera el don de la ubicuidad, es imposible que el viaje se produjera en esas fechas. También se muestra difícil para otras fechas P. M. Cátedra. Sermón, sociedad... A.M.C. García Martínez. La escritura transformada....

92. H. Martin. Le Metier..., p. 165-166. Para el ámbito del arzobispado hispalense es clarificador el trabajo de J.M. Miura Andrades. Frailes, Monjas y Conventos..., que en su capítulo II analiza los vínculos con las diversas instituciones, en especial con los concejos. También las referencias que realiza a los vínculos con las oligarquías locales en el capítulo III.

93. 1495, abril, 24. Écija. AMEc, Actas Capitulares, Leg. 1, f. 382v. En el caso de Écija la vinculación con el concejo y las oligarquías locales de las diversas órdenes mendicantes pueden verse en J.M. Miura Andrades. "Hechos extraordinarios...", especialmente cuando trata de los enterramientos.

94. ACPPE, Peñafiel, 1504. R. Hernández. “Actas de la Congregación...”, AD, II, p. 102.

95. Para el caso de los mendicantes castellanos puede ser ilustrativo el trabajo de M.M. Graña Cid. "Frailes, Predicación y Caminos en Madrid. Un Modelo para Estudiar la Itinerancia Mendicante en la Edad Media". En Caminos y Caminantes por las Tierras del Madrid Medieval. Madrid, 1993, pp. 281-321. 
momentos, pues las Actas del Capítulo Provincial de la O.P. celebrado en Palencia en 1256 establece que

"los priores no envien a los hermanos fuera de los límites de la predicación. Sin una evidente utilidad, y sin el consejo de los sacerdotes, no deben hacerlo. Los que encomienden tales misiones deben señalar bien los términos del destino, de manera que puedan regresar prontamente a sus conventos"96.

Nuestro desconocimiento es mayor para el medio rural puesto que también la documentación relativa a las actividades de predicación es mucho más escasa para estos espacios. Por un lado, porque, como norma general, se nos ha conservado menor información de los lugares menores que de los mayores. En segundo lugar, por la propia excepcionalidad de la predicación en ámbitos rurales centrados seguramente en algunos días al año (las fiestas o votos patronales o alguna celebración importante), mientras que en aquellos lugares donde existían predicadores a la mano podían realizar la predicación cuando fuera necesaria ya fuera para dar gracias o para apaciguar la histeria colectiva ante fenómenos naturales. Por último, otra causa de esta escasez de información es que los grandes predicadores, los mejor formados, aquellos de los que podemos disponer, por su vinculación con otros sectores sociales o instituciones, de más vías de información, no solían realizar estas tareas, encomendadas a predicadores de menor rango -los terminarios- que pasan desapercibidos en el resto de la documentación y de los cuales no nos queda en la mayoría de los casos más que el nombre.

A pesar de estas dificultades hemos de suponer que la labor de predicación en estas villas se desarrolló de las siguientes formas: ya fuera por los propios frailes cercanos a los mismos, procedentes del movimiento eremítico franciscano fundamentalmente, que se encontraban asentados en las ermitas cercanas a tales núcleos de población como nos consta para el caso de Nuestra Señora de la Bella de Lepe ${ }^{97}$; ya fuera por frailes destacados desde los grandes conventos ciudadanos para realizar labores de predicación. Junto a los ya citados acuerdos de los dominicos castellanos en Palencia en 1256, tenemos datos más directos como es la estancia de fray Alfonso, dominico de San Pablo, en Morón de la Frontera ${ }^{98}$. Sin embargo, no parece que ésta sea una tarea grata, por lo que el General dominico debe recordar esta obligación en $1504^{99}$. San Vicente Ferrer se detiene en su camino en la pequeña localidad de Tobarra para predicar brevemente, porque

96. ACPPE, Palencia, 1256. EDIT. R. Hernández. "Pergaminos de la Actas de los Capítulos Provinciales del Siglo XIII de la Provincia de España”. En Archivo Dominicano, IV, 1983, pp. 5-73, p. 13.

97. Los motivos que nos da Rubio son para "que en aquellas soledades pudieran adoctrinar y servir espiritualmente a los pescadores, numerosos en aquellas costas". G. Rubio. La Custodia de Sevilla. Ensayo Histórico sobre sus orígenes, progresos y vicisitudes (1220-1499). Sevilla, 1953, pp. 391-392.

98. 1426, enero, 8. Morón. AMMF, Actas Capitulares, f. 98 r. EDIT. M. González Jiménez y M. García Fernández (Eds.). Op.Cit., p. 134.

99. "Teniendo en cuenta las necesidades de los pueblos y su posibilidad, envíen [los priores] predicadores en las cuaresmas y en las grandes festividades, para consolar a las gentes". ACPPE, Peñafiel, 1504. EDIT. R. Hernández. “Actas de la Congregación...”, AD, II, pp. 19 y 102-103. 
"in ista villa ego penso quod non habetis multas predicaciones" "100, lo cual nos muestra la penuria de este tipo de servicio religioso en el que se encontraban las poblaciones rurales.

\section{LOS TIEMPOS DE LA PREDICACIÓN}

La predicación en sí misma no tiene un tiempo sino que se puede desarrollar en cualquier momento al hilo de la tarea pastoral. De hecho, habría que entender como tal la homilía que, como nos consta para el caso de Écija, donde Juan de Biedma presentó una carta del cardenal "para que cada uno pueda ir a oír los domingos oficios y sermones a do más devoción toviere pidiendo licencia a los curas, los cuales se la den"101. La gran predicación hispana del siglo XV personificada en San Vicente Ferrer demuestra esa inexistencia de un tiempo preciso para la predicación. Con el discurrir de sus caminos y su llegada a las villas el santo dominico realizaba el sermón, sin tener en cuenta para ello la existencia o no de alguna celebración, festividad o el momento del calendario litúrgico ${ }^{102}$.

Ello no es obstáculo para que, aún así, existieran momentos a lo largo del año o del tiempo que fueran más proclives a la realización de la predicación o a dar mayor solemnidad y empaque a la misma.

Los grandes momentos de la predicación son los que se relacionan con las grandes festividades del año litúrgico (Navidad, Cuaresma, Pasión...), en el que destaca la Cuaresma.

Existe la obligación por parte de los dominicos de enviar predicadores a los pueblos en esas fechas y en las grandes festividades locales ${ }^{103}$. Parece ser que los dominicos cumplían con esa obligación pues el único dato que nos consta de un predicador desplazado a una villa lo es para predicar la cuaresma en Morón de la Frontera ${ }^{104}$. Las grandes y largas estancias de fray Álvaro en Sevilla tienen como motivo la predicación de la Cuaresma. En el caso de la catedral sevillana, durante los cuatro domingos de la Cuaresma y el domingo de Pasión se celebraban dos sermones, uno por la mañana y otro por la tarde ${ }^{105}$. De la importancia de tales sermones, quizás los mejor preparados o los realizados por los predicadores más solicitados, da prueba el acuerdo que en 1495 realizan los regidores de Écija "porque

100. CIT. P. M. Cátedra García. Sermón, Sociedad y Literatura..., p. 20.

101. 1501, marzo, 24. Écija. AMEc, Actas Capitulares, Leg. 2, c. 201, 27.

102. Sobre las predicaciones de San Vicente Ferrer pueden consultarse: A.M.C. García Martínez. Los caminos de la predicación de San Vicente Ferrer. Trabajo de Investigación de Tercer Ciclo, Sevilla, 1994, inédito; P. M. Cátedra García. Sermón, Sociedad y Literatura..., que nos aporta importantes datos sobre la labor de predicación, tanto en sus aspectos externos como internos del propio discurso religioso. Más extenso y de gran utilidad A.M.C. García Martínez. La escritura transformada...

103. ACPPE, Peñafiel, 1504. R. Hernández. “Actas de la Congregación...”, AD, II, pp. 19, 102-103.

104. 1426, enero, 8. Morón. AMMF, Actas Capitulares, f. 98 r.

105. ACS, Mesa Capitular. Comunal n. 1079 (6). Costas del Comunal (1477-1485). Agradecemos a la Dra. Montes Romero-Camacho el facilitarnos la información sobre la existencia de tales menciones documentales. 
puedan oír los sermones desta Cuaresma, de mudar los cabildos esta Cuaresma y se hagan martes, jueves y sábado"106.

El otro gran momento de la predicación son las fiestas patronales o locales. Es lógico pensar que para las grandes celebraciones se intentara por todos los medios contratar los servicios de un predicador con objeto de dar esplendor y mayor utilidad a la festividad religiosa.Así nos consta que ocurría en Écija. La ciudad tenía tres grandes festividades durante el periodo medieval, en las cuales tenía hecho voto: San Pablo (resultado del milagro que realizó el Santo en la ciudad en 1436) que se celebra el 29 de enero; Santa María Candelaria, que se realizaba el 2 de febrero; y San Marcos, cuya festividad aparece en el calendario el día 25 de abril. Los capitulares astigitanos acuerdan en 1495 repartir la predicación entre franciscanos y dominicos, únicas comunidades existentes en la ciudad en ese momento. Los dominicos predicarían el día de San Pablo. Los franciscanos lo harían el día de la Candelaria, quizás por su mayor vinculación mariana. El sermón del día de San Marcos se rotaría anualmente entre franciscanos y dominicos "porque se tenga igualdad entre ellos, e queste año comience Santo Domingo"107.

Los sermones podían tener un carácter penitencial (lanzando una llamada al arrepentimiento), disciplinar y devocional, donde los santos eran los modelos que animaban al fiel a reforzar su compromiso en la fe. Sin embargo, ajeno al ciclo litúrgico y a las festividades locales, algunos acontecimientos requerían la existencia de un sermón como necesidad de llenar el ciclo festivo o penitencial. Las mismas reciben el apelativo de predicaciones extravagantes. Se ha afirmado con razón que no se comprende una fiesta medieval en la que lo sacro y lo profano no se entremezclen $^{108}$. La fiesta medieval es por definición religiosa, al igual que lo es el actuante en las mismas: el Hombre Medieval. Por ello, la predicación, como labor pastoral pero también como espectáculo, no puede faltar en los grandes acontecimientos sean éstos de carácter sacro o profano. Las predicaciones se producen en todas las fiestas y en cualquier momento de angustia o temor que lleve aparejado la realización de rogativas o procesiones.

En el caso de Jerez así se hace constar puesto que fray Juan Rapado, el Comendador de la Merced, aparece definido por los oficiales del concejo jerezano como "noble persona e a fecho e fase muy benignamente con grand deuoción e ha de faser todos los sermones en las procesyones e rogatiuas que en esta ciudad fasta aquí son fechas e se an de faser" ${ }^{\prime 09}$. Cuando en 1495 los oficiales de la ciudad de Écija acuerdan hacer una procesión para el día de San Matías Apóstol que vaya a la ermita de Nuestra Señora del Valle, se establece que, para que "vayan más suntuosamente que ser pueda", además de la presencia de las cofradías de

106. 1495, marzo, 4. Écija. AMEc, Actas Capitulares, Leg. 1, f. 373r.

107. 1495, abril, 24. Écija. AMEc, Actas Capitulares, Leg. 1, f. 382v.

108. Referido a nuestro ámbito cronológico y espacial puede ser de utilidad para esta conceptuación la obra de A.R. Romero Abao. "Las Fiestas de Sevilla en el siglo XV", CEIRA, 2. Las Fiesta de Sevilla en el siglo XV. Otros Estudios. Madrid, 1991, p. 12-178. Una reflexión más amplia en M.A. Ladero Quesada. Las fiestas en la cultura medieval. Barcelona, 2004.

109. 1410, junio, 30. Jerez de la Frontera. Actas Capitulares, fol. 97v. del cuaderno original, 196-197 de la transcripción de A. Muñoz. Los fechos.... 
la ciudad, se ordene a Diego Méndez librar para cera y para el predicador 1000 maravedís ${ }^{110}$. De nuevo en Écija en 1511 se realiza una procesión que va a Nuestra Señora del Valle, para pedir que se quitase la "cizaña" de la Iglesia al término de la cual se hizo un servicio de sermón por los dominicos, que recibieron por ello 200 maravedís ${ }^{111}$. La vinculación entre sermón y procesión se manifiesta también en Carmona donde Juan Mateos Castaño, el fundador del convento de Santa Ana, pedía en 1504 al cabildo que prohibiera echar estiércol junto a la esquina de la iglesia de Santa Ana donde él estaba construyendo una cruz. Solicita, además, que una vez "alinpiada la dicha tierra, faga merçed della a la dicha iglesia ... para que la tenga linpia por donde puedan oír los sermones y las procesiones generales"112.

Se desarrollaron sermones en las fiestas de la vida y la muerte (nacimientos, bodas y muertes) de los grandes personajes locales, magnates o personas reales, etc. El regidor de Écija Alfonso de Zayas ordenaba por su testamento que el día de su finamiento y enterramiento un fraile de Santo Domingo haga un sermón en el dicho monasterio, dándole su derecho ${ }^{113}$.

Igualmente en Écija hay constancia de la predicación de un sermón por parte de fray Juan de Pro, dominico, en 1503 por las alegrías del nacimiento del príncipe ${ }^{114}$ y fray Diego Méndez, franciscano, quien predicó el sermón en la procesión que se hizo a Nuestra Señora del Valle el día del alumbramiento de la princesa en $1503^{115}$.

La vida del hombre medieval se encuentra en un alto grado sometida a los designios de la Naturaleza, que condiciona tanto su forma de vivir como de morir. Ante la ineficacia de sus medios, el hombre sólo puede recurrir a la protección de la divinidad quien, en última instancia, es la que puede devolver la Naturaleza a su cauce normal, al tener el control sobre la misma. Resultado de ello es que ante cualquier catástrofe afloren con mayor fuerza los sentimientos religiosos de las poblaciones que ven en las mismas los presagios de un castigo divino en función de los pecados, por otra parte demasiado frecuentes, de los ciudadanos o sus rectores en lo civil (ya sean los miembros del concejo o la propia monarquía); o en lo religioso ${ }^{116}$. Ante la catástrofe solo cabe impetrar el perdón de Dios o su ayuda. En tales circunstancias, con un enfervorizado celo religioso, las palabras del predicador, ya sea para poner de manifiesto los vicios y pecados cometidos por los que se provoca el siniestro, o para llevar el consuelo a las gentes asustadas, se hacían cada

110. 1495, febrero, 20. Écija. AMEc, Actas Capitulares, Leg. 1, f. 371r.

111. 1511, diciembre, 3. Écija. AMEc. Actas Capitulares, Leg 2, c. 230, 37.

112. Archivo Municipal de Carmona (AMCar), Actas Capitulares, 1504, f. 37. REG. M. González Jiménez. Catálogo de la Documentación Medieval del Archivo Municipal de Carmona. (1475-1504). Sevilla, 1981, t. II, n. 1952.

113. 1491, agosto, 16. Écija. Archivo del Palacio Arzobispal de Sevilla (APAS), leg. 2010, Justicia-Ordinarios, ff. 409r-416v.

114. 1503, abril, 24. Écija. AMEc, Actas Capitulares, Leg. 2, c. 205, 7.

115. 1503, marzo, 16. Écija. AMEc, Actas Capitulares, Leg. 2, c. 204, 31.

116. Puede ser de utilidad en ese sentido J.M. Miura Andrades. "Hechos extraordinarios..." y otras aportaciones en A. Martín Pradas y I. Carrasco Gómez (Dirs.). Actas de las XI Jornadas de Protección del Patrimonio Histórico de Écija. "Acontecimientos naturales y sobrenaturales en la ciudad de Écija”, Écija, 2014. 
vez más necesarias. Para el caso sevillano tenemos un par de ejemplos que pueden ser muy ilustrativos de lo que aquí comentamos sobre los fenómenos naturales.

El año 1464 no fue precisamente bueno para la ciudad de Sevilla. En los años anteriores se había producido el enfrentamiento entre los dos arzobispos Fonseca (tío y sobrino), quienes habían permutado los arzobispados de Santiago y Sevilla. Cuando el tío, Alonso de Fonseca "el Viejo" quiso retornar a la sede hispalense su sobrino se negó a devolver, como estaba acordado, la sede y marcharse a la de Santiago. Se armó la ciudad y se desató una lucha de bandos que obligaron a poner en entredicho a Sevilla por parte de Alonso de Fonseca "el Viejo". La situación no se resolvió hasta la venida de Enrique IV a Andalucía a fines de 1463 y el prendimiento de Alonso de Fonseca "el Joven" al que se le obligó a partir para Santiago a inicios de 1464. No acabaron aún las discordias sino que a lo largo de todo el año 1464 el arzobispo no pudo entrar en la ciudad y tomar posesión de su sede, ante la oposición tanto de la ciudad como de algunos consejeros de Enrique IV que lo indispusieron con el monarca que le mandó "suspender la posesión, embargarle las rentas y formarle proceso" ${ }^{117}$. La situación no se aclaró hasta fines de este año 1464.

Precisamente en los momentos en que la ciudad se encontraba sin prelado, uno en Santiago y otro suspenso en su posesión, sucedió un fenómeno que debió minar el sentimiento religioso, por otra parte ya muy aflorado en el pueblo por las tensiones entre los dos Fonseca.

"El 18 de febrero del mismo año de 1464, prodigios terribles amedrentaron a los moradores de Sevilla", como nos cuenta Palencia"18, puesto que "Un sólo golpe de viento garbíneo y no tempestuoso, sino mezclado con alguna lluvia, destruyó aquella parte del alcázar donde el rey habitaba ordinariamente y dejó en un instante arrasado un frondosísimo jardín cubierto de muchos y muy hermosos árboles... las murallas de la ciudad que cercaban la parte anterior de éste vinieron a tierra y las cúpulas de las torres quedaron como cortadas con una espada... el acueducto, de fábrica de ladrillo tan fuerte que hubiera resistido muchos días los esfuerzos destructores de un ejército enemigo, se derrumbó de repente sin movimiento alguno de tierra, ni golpe furioso de viento y lo que es más de maravillar, sin producir el menor estrépito, a pesar de haber caído sobre piedras. Quedaron descubiertos muchos sepulcros... todos estos y otros infinitos desastres ocurrieron en tan cortos momentos que apenas hubieran bastado para abrir y cerrar tres veces los ojos" 119 .

La situación del pueblo, sometido a lo largo de un año a luchas banderizas, enfrentamientos que se asemejaban a un cisma, entredicho, no posesión del prelado, etc. debió ser tal que temían que todo ello no fuese más que el castigo divino que

117. D. Ortiz de Zúñiga. Anales..., t. III, p. 28. Para el desarrollo de los acontecimientos entre los dos arzobispos Fonseca puede seguirse J. Sánchez Herrero. "El largo mantenimiento de unas Reformas Religiosas. 1433-1474”, Historia de la Iglesia de Sevilla. Sevilla, 1992, pp. 243-299, pp. 253-255. A. Franco Silva. "El Arzobispo de Sevilla Alonso de Fonseca el Viejo. Notas sobre su vida", Boletín de la Real Academia de la Historia, tomo 196, Cuaderno 1, 1999, págs. 43-92.

118. A. Palencia. Crónica de Enrique IV. Ed. BAE, Madrid, 1973, p. 144.

119. Ibidem. 
pesaba contra la ciudad por los pecados de sus moradores, sus dirigentes civiles y religiosos y la propia monarquía. Enrique IV envió desde Jaén, donde estaba, que viniese a predicar a Sevilla un cierto religioso

"ordenándole que combatiese en sus sermones la estupefacción de los ciudadanos, persuadiéndoles de que en todos aquellos prodigios y en otros del mismo género para nada intervenía la mano de la Divinidad, sino causas enteramente naturales" 120 . También "por respeto a los magistrados de Sevilla, y principalmente por las súplicas de Juan Manuel de Lando, predicó el obispo de Ampurias......que todo había sido efecto de la violencia de un tifón o contra la interpretación mejor y más exacta de los que los consideraban como presagios de la inmediata desgracia del Rey impio" ${ }^{\prime 21}$.

Hemos preferido dejar que nos narrara el acontecimiento el propio cronista y alargar la cita pues de ella se deduce que la predicación, en muchas ocasiones, se muestra como antídoto de situaciones de crispación social, siendo utilizada, como en este caso, con un claro fin político, incluso ajeno a la política local y referido a la evolución general de los acontecimiento en el conjunto del Reino.

En el segundo de los ejemplos, el caso es el contrario. El predicador incide en los pecados cometidos y los vincula al castigo recibido, aunque siempre de su tarea se intenta obtener la no comisión de nuevos pecados y la finalización de los vicios que habían dado lugar a la ira divina. Se trata del terremoto de 1504 que asoló la mitad sur peninsular y el arzobispado de Sevilla con una especial virulencia. El terremoto, unido a un fuerte viento, se produjo el Viernes santo 5 de abril por la mañana, se levantó el río (¿tsunami?) que parecía que se entraría en la ciudad y la inundaría, se cayeron algunas iglesias y casas y "quedó la ciudad tan poseída de temor que los predicadores tomaron motivos para remediar culpas". El texto de unas cartas de los reyes a los dos cabildos nos informa algo más del ambiente vivido: "e pues plugó a Nuestro Señor enviar sobre esa ciudad tantos males, peste e hambre, no ceséis en implorar su misericordia con vuestros ruegos e en procurar aplacar la su justicia"y la otra "por lo que cumple implorar la misericordia de Nuestro Señor, que en tal manera demuestra su ira contra los pecadores"122.

Ante ello se ordenó que se predicara con gran fervor a las rameras y a las mujeres de la casa pública, haciendo responsable a estos pecados públicos del castigo divino. El estado psicológico de la población es claramente definible gracias a una carta enviada por las mujeres públicas de Carmona a su cabildo ${ }^{123}$.

Junto a estos momentos de angustia también en los de grandes alegrías se desarrollaron predicaciones. Ya vimos como los nacimientos dan lugar a predicaciones. Las victorias militares conllevaban la celebración de fiestas en las que no

120. Ibidem.

121. Ibídem.

122. D. Ortiz de Zúñiga. Anales..., t. III, p. 192-194 donde se puede ver la descripción de los desastres.

123. M. González Jiménez. El Concejo de Carmona a fines de la Edad Media (1464-1523). Sevilla, 1973, pp. 194-195. 
podían faltar los servicios religiosos. No sabemos si existió la predicación, pero sería lo más lógico, cuando en 1407 se les dieron a los frailes de San Agustín de Sevilla 500 maravedís por el trabajo que tuvieron, a la vuelta de conquistar Zahara, en el recibimiento del pendón de la ciudad ${ }^{124}$. En el caso de Écija tras la victoria de Saelices predicó el guardián de San Antonio ${ }^{125}$.

Además de todos estos momentos, sean de zozobra o de alegría, la presencia de un importante predicador en el lugar era suficiente para que se aprovechara la ocasión para que realizara un sermón. En el caso de fray Álvaro de Córdoba o de Zamora se hace constar el hecho de realizar un sermón diario ${ }^{126}$.

Nos consta que la predicación de la Bula de Cruzada se desarrolló en el Reino de Sevilla con insistencia siendo como era ciudad y territorio de frontera y muy vinculada con el propio hecho bélico frente a los musulmanes ${ }^{127}$. Tan sólo conocemos a un predicador de la misma por su nombre. Se trata del dominico fray Alonso de Espina ${ }^{128}$.

En algunas ocasiones tales predicaciones escondían posturas falsarias. En Jerez en el cabildo se presentaron el guardián de San Francisco, el prior de Santo Domingo y otros frailes y clérigos y explicaron que en la ciudad se estaba predicando una bula de San Juan de Acre de Sevilla con indulgencias que no tenía y perdones que no se contenían en la bula, a precio de 40 maravedís y sin autoridad del Santo Padre. Fue llamado el predicador, un fraile trinitario, quien testificó que la bula se la dio el vicario Martín García y lo que predicaba se lo mandaron predicar así. El predicador fue preso, se mandó cesar en la predicación y embargar lo recaudado hasta que el obispo proveyese ${ }^{129}$.

\section{LOS CONTENIDOS DE LA PREDICACIÓN}

El General dominico Bandelli nos da las claves de la predicación cuando afirma que:

"Los Predicadores se llaman asi por el oficio de predicar. Y este oficio como propio nuestro, debemos ejercerlo con diligencia. Por consiguiente advierto, en primer lugar al Padre Vicario y a los presidentes de los conventos, gravando sobre ellos sus conciencias, que no expongan a la predicación sino a aquellos que son suficientes

124. 1407, noviembre, 15.AMS, Papeles del Mayordomazgo, año 1407, n. 108.

125. 1504, abril, 19. Écija. AMEc, Actas Capitulares, Leg. 2, c. 208, 36.

126. 1420, marzo, 6. Se hace constar que el pago es "por el afán y trabajo que fray Álvaro diariamente se tomaba por sus sermones". AMS, Papeles del Mayordomazgo, año 1419, n. 98.

127. Un ejemplo claro de las celebraciones que se realizaban para predicar la bula de Cruzada, aunque referido al siglo XVII, se encuentra en A. Sánchez Gordillo. Religiosas Estaciones que frecuenta la Religiosidad Sevillana. Sevilla, 1982, pp. 107-113, donde consta la realización de un sermón por "un buen predicador de fama que el tribunal convida para ello".

128. D. Ortiz de Zúñiga. Anales..., t. III, p. 12.

129. 1483, marzo, 17. Jerez. Actas Capitulares de Jerez, fol. 77. EDIT. H. Sancho de Sopranis. “San Francisco...", pp. 522-523. 
en doctrina y graves en las costumbres y de una edad conveniente. Incúlquenles además que no prediquen cosas escandalosas y litigosas y no ataquen a los prelados y personas honorables, sino que prediquen la doctrina evangélica y cuanto favorezca la paz y la edificación"130.

Por lo tanto tendríamos que los contenidos de los sermones han de ser eminentemente de carácter evangélico, destinados a llevar el conocimiento de la doctrina a todas las capas del pueblo cristiano. Pero, junto a este fin o en indisoluble ligazón con él, aparecen otros temas, como son la corrección de los pecados públicos (ya sean de los magnates o del pueblo), que son objeto del contenido de la predicación y en ocasiones se convierten en cosas "escandalosas y litigosas". Hemos de ser conscientes que con la predicación se imparte doctrina, pero no sólo. Existen intereses de todo tipo (políticos, pecuniarios, territoriales...), todo eso que podríamos englobar bajo la moderna denominación de "propaganda".

Lamentablemente, para el caso del arzobispado hispalense no se nos han conservado repertorios de sermones que nos pudieran indicar el contenido y facilitar un estudio estadístico de los mismos como para otros ámbitos territoriales ${ }^{131} \mathrm{o}$ cronológicos $^{132}$. Aún así podemos realizar una catalogación genérica del contenido de los sermones sevillanos siguiendo las indicaciones de los grandes rasgos de las predicaciones conocidas. Así, tendríamos:

- Sermones cuyos contenidos son básicamente de carácter teológico o eminentemente de catequesis formativa del pueblo. Que los mismos se realizaron en la diócesis hispalense parece meridianamente claro y a ello hacen referencias continuas las justificaciones de limosna y pago de predicaciones. Por ejemplo, una y otra vez se delimita tal función en los pagos del concejo de Sevilla: en 1420 cuando predicó fray Álvaro se dice que de sus sermones "se seguía servicio de Dios y provecho y salud de las almas de los vecinos y moradores, quitándose muchos pleitos y escándalos"133; cuando se conceden 1000 maravedís a fray Manuel para comprar el libro de Nicolao de Lyra se hace porque de ello "se ha de seguir salud y mejoramiento de las almas de los muchos cristianos"134; o cuando se paga por su trabajo a fray Antonio de Alcalá se hace constar que es por "el trabajo que se tomaba en predicar la palabra de Dios"135.

- Sermones que se centran en sus contenidos a la reforma y corrección de las costumbres, o a la represión de los pecados colectivos, o de algunos grupos. El caso más claro quizás sea el de fray Pedro de Almansa. Es de los esca-

130. ACPPE, Peñafiel, 1504. R. Hernández. “Actas de la Congregación...”, AD, II, p. 102.

131. Para Bretaña puede verse H. Martin. Les Ordres Mendiants en Bretagne. (Vers 1230-vers 1530). París, 1975, pp. 311-317. También para el caso de la predicación vicentina se han conservado un importante corpus que permite este tipo de acercamiento.

132. M.A. Núñez Beltrán. La oratoria sagrada de la época del barroco: doctrina, cultura y actitud ante la vida desde los sermones sevillanos del siglo XVII. Sevilla, 2000.

133. 1420, marzo, 6. AMS, Papeles del Mayordomazgo, año 1419, n. 98.

134. 1427, octubre, 1. AMS, Papeles del Mayordomazgo, año 1427, n. 29.

135. 1460, enero, 23. AMS, Papeles del Mayordomazgo, 1458-1459 (52). 
sos casos de los que nos consta el contenido de la predicación, aunque sea reportado por sus denunciantes. En él se centra en el ataque a los clérigos seculares sevillanos y a sus vicios. Lo hace de una forma directa (quizás en exceso, lo que le valió su denuncia), sin mediar ningún tipo de recato:

"que los clérigos malos non eran saçerdotes de Dios, sinon del diablo, e que fasían sacrifiçio al diablo... ... e robauan a las eglesias e non las seruían, e que preçiauan más beuer por las tauernas e jugar dados e andar por las plaças uagabundos... ... e que se pagauan más andar a caça con vn galgo..."

aunque sin dejar de alabar a aquellos que cumplían con sus obligaciones y tenían capacidades

"no lo digo por lisonja, que vos digo que es buen clérigo e buen eclesiástico e leye bien e canta bien e entiende lo que leye. E otrosy que quando era sacristán, que barrya e regaua bien la eglesia e alinpiaba los altares" ${ }^{\prime 136}$.

Ya hemos analizado, en esta crítica a los pecados públicos o privados, las predicaciones que se sucedían ante acontecimientos catastróficos, como en el caso del terremoto de 1504, pero un caso nos demuestra como en ocasiones estas denuncias provocaron no pocas tensiones y situaciones conflictivas. En 1506 Écija elevaba diversas quejas sobre el funcionamiento de los oficiales a la Corona y entre ellas que estando un día predicando el guardián reprendió diversos vicios y pecados, entre ellos el de las blasfemias, indicando que las mismas no se castigaban. En el sermón se encontraba presente la justicia y,

"paresciéndole que le reprendía y que por él se decía, como hombre que tenía razón de lo pensar, porque él sostiene en esta ciudad a los blasfemadores, levantose a responder con mucha soberbia al guardián, en presencia de todo el pueblo, e dixo que merecía ser apedreado el guardián y que mentía y otras muchas deshonestidades, donde se puso el pueblo a mucho peligro, que si el Guardián respondiera..." ${ }^{137}$.

Dentro de esta corrección de las actuaciones de las instituciones civiles y religiosas, así como del conjunto social, podríamos distinguir a su vez dos marcos de actuación más definidos. Por un lado, el cese de aquellas acciones que desestabilizaban la propia dinámica social (las pacificaciones de bandos y enemistades). Por el otro, la integración dentro de la sociedad de aquellos que, por razón de sus creencias religiosas, se encontraban al margen de la misma (conversión de judíos y musulmanes). Más que tratarse de contenidos mismos de la predicación habría que analizar los mismos como consecuencia directa de ella.

136. ACS, sin catalogar. EDIT. M. González Jiménez. “Nivel Moral...”, pp. 202-204.

137. Archivo General de Simancas (AGS), Cámara-Pueblos, Leg. 7, fol. 177. 


\section{LAS CONSECUENCIAS DE LA PREDICACIÓN}

\subsection{La pacificación de bandos o enemistades}

En una sociedad violenta en lo estructural, la salida airosa a situaciones de tensión tiene que venir de la mano de lo sobrenatural, de aquello que hace que el hombre se sienta limitado en sus actuaciones. La Iglesia se mostró desde los primeros tiempos como garante de la paz pública y continuó esta tarea siempre que pudo. En este sentido pacificador actúan la mayor parte de los predicadores sevillanos. En 1420, entre otras razones, se da mandamiento al mayordomo para que diese ciertos maravedís a fray Álvaro de Córdoba "por el afán y trabajo que fray Álvaro diariamente se tomaba por sus sermones......quitándose muchos pleitos y escándalos"138. En 1442 es fray Miguel Rapado, obispo de Grosopoli, quien "ha hecho muchos servicios con sus sermones en esta ciudad a las personas que los oyen de deudas y usuras que se perdonan los unos a los otros" ${ }^{139}$. Mucho más clara es la actuación que desarrolló fray Miguel en El Puerto de Santa María en 1484:

"En este dicho dia, viernes de la Crus, en auiendo acauado de predicar fray Miguel, maestro en Santa Teología, del ábito de San Francisco, resydente en el monesteryo de San Francisco de Xeres, e por su cabsa e ruego se fisieron ante mí Ferrando de Carmona, scriuano público a la puerta de la yglesia del Poso Santo estos perdones: Primeramente perdonaron Juan de Fuentes e Antón Vernal y Juan Fernández, hermano del dicho Juan de Fuentes, a Francisco Martín la muerte de su hermano Andrés de Fuentes. Asymismo perdonó la mujer del almirante viejo la muerte de su fijo... Ysabel Martines de Utrera a Alonso Moller la muerte de su hermano... Bartolomé Sanches de Frexenal una ynjuria que le fisieron unos cryados de Francisco de Valladolid... Luys de Merode... a Juan de la (roto), vecino de Merode, la muerte de Ferrand Gonzales del Maço, su tío... Ynés Martines y Juana Martines... a Juan Arraes la muerte de su hermano... Pedro Sanches... la muerte de su primo Andrés Martines, que lo mató Pedro Dias Madalena... con condición de que no se le porna delante... Teresa Gonzales la Beserra la muerte de su hijo... Ferrand Gomes a Sancho García, tejero, trescientos ochenta marauedís que le deue... Bartolomé Gil a Jun Castado la muerte de su hermano... Antonia Martines... a Esteuan la muerte de su marido... Pedro Ballesteros a su muger un adulterio que le fiso... Juan García Conejo la muerte de su tyo Antón García Conejo... Francisca Bernal... a Esteuan la muerte de su sobrino... Catalina Martines... la muerte de su hermano, fijo del almirante... Pedro Niño a Pedro de Masa la muerte de su sobrino... Antón Gonzales a su yerno Diego Arraes una ynjuria... Pedro, fijo del almirante, a Juan Miguel la muerte de su hermano. A los quales perdones fueron presentes mui grand cantidad de gente que oyó al dicho frayle..." 140.

138. 1420, marzo, 6. AMS, Papeles del Mayordomazgo, año 1419, n. 98.

139. 1442, marzo, 28. AMS, Papeles del Mayordomazgo, 1438-1441.

140. 1484, abril, 16. Archivo de Protocolos de Jerez, I1, Varios, siglo XV, fol. 180 v. EDIT. H. Sancho de Sopranis. "San Francisco...", pp. 526-527. 
7.2. La conversión de las minorías religiosas

La predicación castellana aparece durante la Baja Edad Media, al menos en los predicadores mejor conocidos, marcada por lo escatológico y referida a la conversión de las minorías no cristianas, y a los judíos en particular. Ejemplo son los grandes predicadores San Vicente Ferrer y Alonso de Espina.

Cuando en 1426 el concejo de Sevilla ordenaba al mayordomo que diese a fray Álvaro de Córdoba otros 1000 maravedís, además de los concedidos con anterioridad, lo hace para su mantenimiento los días que estuviese "predicando en esta ciudad a los cristianos y demás vecinos y moradores", que hemos de suponer que serían judíos y mudéjares ${ }^{141}$.

Sin embargo, el contenido de los sermones no siempre era formativo para tales minorías sino que, en alguna ocasión, provocaba, entre los que los escuchaban, un sentimiento antijudío importante. Así ocurrió en 1450 cuando la judería sevillana estuvo a punto de ser asaltada por causa del sermón de un fraile franciscano, cosa que evitaron los oficiales del concejo y recibieron por ello el agradecimiento de Juan II $^{142}$.

En otras ocasiones, el sermón no intenta soliviantar la animadversión popular hacia los judíos o conversos sino poner en marcha mecanismos institucionales de control de los mismos. Los oficiales del concejo de Écija se vieron condicionados en su decisión de reclamar la presencia de los inquisidores en 1487 por un sermón realizado por un dominico, pues

\begin{abstract}
"antes que entrasen en el cabildo avía predicado el Presentado, Prior de Santo Domingo, en la apelación, en que dixo ciertas cosas tocantes a la herejía, e que dixo que requería a los caballeros del regimiento desta cibdad quellos ficieren saber a los reyes como en esta cibdad había grandes herejías, que sus altezas manden a los inquisidores que vengan a esta cibdad. Mandaron escribir que vaya Fernando de Zayas al Real ..."143.
\end{abstract}

En el caso de los moriscos, para el arzobispado sevillano, se recurrió, en 1505, a la predicación de fray Martín de Ullate, religioso agustino, encargado por fray Diego de Deza, arzobispo de Sevilla, para la conversión de los moriscos mediante la predicación, lo que le había dado excelentes resultados en su anterior diócesis, Palencia, y los volvió a dar en la hispalense ${ }^{144}$.

141. 1426, marzo, 10. AMS, Papeles del Mayordomazgo, año 1426, n. 69

142. 1450, junio, 2. Salamanca. AMS, Actas Capitulares, 1450, s.m., fol. 22. REG. M.J. Sanz y M.I. Simó. Catálogo de Documentos contenidos en los libros del Cabildo del Concejo de Sevilla. Sevilla, 1975, n. 308.

143. 1487, agosto, 22. Écija. AMEc, Actas Capitulares, Leg. 1, f. 249r-v.

144. J. Sánchez Herrero. "La Reforma..., pp. 316. 


\subsection{El auge y la potenciación de devociones}

Dentro de la labor formativa del pueblo, la potenciación de determinadas devociones vinculadas a la propia orden o a algunos conventos concretos, donde se guardan reliquias o imágenes o se vinculan hechos sobrenaturales, es uno de los fines que persiguen determinadas predicaciones ${ }^{145}$. Hemos visto cómo ocurría así para el caso de Écija, donde se repartían el ciclo festivo de la ciudad los franciscanos y dominicos. Hemos de suponer que se aprovecharían tales celebraciones para potenciar unas devociones que, en última instancia, se habrían de plasmar en un mayor control sobre la piedad popular de las distintas órdenes.

\subsection{Las retribuciones de las predicaciones}

La primera de las retribuciones que recibe el predicador por sus sermones es la propia satisfacción del deber cumplido. Junto a ella, también aparece un control, que no hay por qué considerar negativo, de las conciencias de los fieles, que, evidentemente, se traduce en un aumento de su autoridad moral, que se ha de transformar en un aumento de las donaciones hacia la institución que representa o hacia su propia persona. Por último, se da también una retribución económica directa.

Es difícil evaluar el precio de un sermón o el salario de un predicador. Este va a depender de la categoría del predicador, de la institución que contrata sus servicios y del servicio contratado (la festividad concreta y su importancia dentro del calendario). A pesar de ello, podemos dar algunos datos al respecto.

Fray Álvaro de Córdoba recibió del concejo sevillano en 14206172 maravedís por su estancia en Sevilla de 174 días, lo que nos sitúa, si hacía un sermón diario, en algo más de 35 maravedís su salario ${ }^{146}$, cifra que se corresponde con lo dotado el año siguiente, al que se le añadieron 200 maravedís a su partida ${ }^{147}$.

En 150 maravedís se estimaba el salario del predicador de la Cuaresma en Morón en $1426^{148}$, aunque ese mismo año fray Álvaro de Córdoba cobró 2000 maravedís durante su predicación en la Cuaresma sevillana ${ }^{149}$.

Los pagos a los predicadores que contrataba el cabildo catedral sevillano entre los años 1479 y 1483 oscilan, para el primero de los años, entre los 60 y los 100 maravedís, siendo la más frecuente la primera de las cantidades. En el último, la tónica sitúa el salario en 92 maravedís $^{150}$.

145. A. García de la Borbolla. "Algunas consideraciones sobre la predicación medieval a partir de la hagiografía mendicante”, Erebea. Revista de Humanidades y Ciencias Sociales, Núm. 1 (2011), pp. $57-82$.

146. 1420, marzo, 6. AMS, Papeles del Mayordomazgo, año 1419, n. 98.

147. [1421]. AMS, Papeles del Mayordomazgo, año 1420, n. 68-XXI.

148. "Dy a frey Alfonso, doctor de Sant Pablo, porque siruió aquí la Quaresma, çiento e çincuenta maravedís". AMMF, Actas Capitulares, f. 98 r.

149. 1426, febrero, 11. AMS, Papeles del Mayordomazgo, año 1425, n. 37; y 1426, marzo, 10. AMS, Papeles del Mayordomazgo, año 1426, n. 69.

150. ACS. Mesa Capitular. Comunal n. 1079 (6). Costas del Comunal (1477-1485). 
Frente a ello, en Écija las grandes festividades tenían asignado un salario para el predicador, que oscilaba entre los 100 maravedís que cobró en 1503 fray Juan de Pro $^{151}$, y los 200 maravedís que se le asignaron en 1503 y 1504 a fray Diego Méndez ${ }^{152}$.

Además de estas cantidades se solía completar, posiblemente como una prima por la calidad del sermón, la dotación con un añadido en especie. Esa era una de las razones que tuvo el concejo de Jerez para hacer limosna a los observantes franciscanos pues consta que lo hacen porque "son muy pobres, e los desta çiudad an devoçión en sus vidas como en sus sermones"153. También el concejo de Sevilla ayudó a fray Álvaro a construir Escalaceli "en atención a los muchos y continuos trabajos que el dicho maestro se tomó en Sevilla en sus sermones"154. Los frailes de Santo Domingo de Écija recibieron en 1501 un carnero y dos arrobas de vino por haber predicado el día de San Marcos fray Alejos ${ }^{155}$.

\section{CONClusiones}

La predicación es una vocación consustancial con la existencia de las propias órdenes mendicantes y su vinculación con la tarea pastoral. En el arzobispado de Sevilla durante la Baja Edad nos es posible conocerla por la interrelación de los frailes mendicantes, sus conventos y monasterios con la sociedad y, especialmente, con las instituciones concejiles. Las actas capitulares y la documentación económica nos permiten conocer la tipología de los predicadores, tanto terminarios como celebridades locales y profetas itinerantes, destacando entre estos últimos la figura de fray Álvaro de Zamora o de Córdoba. Nos consta que casi la totalidad de ellos eran doctores en Teología y pertenecían mayoritariamente a las dos grandes órdenes mendicantes: franciscanos y dominicos.

Las predicaciones son esencialmente urbanas pero cada convento delimita un ámbito de influencia desde el que ejerce su acción pastoral, que incluye el medio rural y los núcleos menores de población. Estos nos son peor conocidos por la falta de documentación.

La predicación no tiene un tiempo pero si tiene unos tiempos más proclives a la realización de la misma. Las grandes celebraciones del calendario litúrgico, especialmente la Cuaresma, las fiestas locales y patronales, cualquier fiesta (nacimientos reales, bodas, muerte, victoria militares...) o temor (catástrofes, peligros, crisis políticas...) se acompañan con sermones.

151. 1503, abril, 24. Écija. AMEc, Actas Capitulares, Leg. 2, c. 205, 7.

152. 1503, marzo, 16. Écija. AMEc, Actas Capitulares, Leg. 2, c. 204, 31; y 1504, abril, 19. Écija. AMEc, Actas Capitulares, Leg. 2, c. 208, 36.

153. Actas del Cabildo de Jerez. [Papel suelto]. EDIT. H. Sancho de Sopranis. "San Francisco...", p. 515 , nota 63 .

154. 1424, junio, 26. AMS, Papeles del Mayordomazgo, año 1424, n. 17.

155. 1501, mayo, 12. Écija. AMEc, Actas Capitulares, Leg. 2, c. 202, 5. 
Lamentablemente no tenemos demasiada información sobre el contenido de la predicación. Había sermones catequéticos, otros fueron disciplinares o de corrección de los pecados y costumbres, otros se centraron en los peligros de la herejía y de la disidencia religiosa.

Mejor informados nos encontramos sobre sus consecuencias, ya fueran éstas la pacificación de bandos o enemistades, la conversión de minorías religiosas, el auge y apoyo a devociones o la retribución, monetaria o de otro tipo, a los frailes que predicaban, a las comunidades conventuales que los formaban o a los monasterios donde la predicación se realizaba.

Por ello, la predicación se muestra así controladora de las consciencias, conformadoras de una moral y de un estado de ánimo de la colectividad, sea este positivo o negativo, al tiempo que, como servicio prestado a la misma. Por lo cual se convierte en una forma de incardinación social y generadora de actitudes compensatorias por parte de los rectores de la comunidad, sean estas actitudes concretadas en un pago salarial o en un débito moral hacia la comunidad religiosa a la cual el predicador pertenece. Es un síntoma de la imbricación de los mendicantes en el sistema urbano.

\section{BiBLIOGRAFÍA}

Aramburu Cedoya, Ignacio. "La Provincia de Castilla en los años 1505-1525. Notas Complementarias", Archivo Agustiniano, Vol. LIX, n. 175, 1965, pp. 5-48, p. 33.

Cátedra García, Pedro Manuel. Dos estudios sobre el sermón en la España medieval. Barcelona, 1981.

- Sermón, Sociedad y Literatura en la Edad Media. San Vicente Ferrer en Castilla (1411-1412). Salamanca, 1994.

—. "Nuevas aportaciones al corpus de la predicación castellana medieval", Studia in Honorem Germán Orduna. Alcalá de Henares, 2001, pp. 181-194;

_. "Últimos restos de la predicación castellana de san Vicente Ferrer", en "Pulchre, bene, recte”. Estudios en homenaje al prof. Fernando González Ollé, Pamplona, 2002, pp. 285-302.

Cortes de los Antiguos Reinos de León y Castilla. Editado por Real Academia de la Historia. Madrid, 1861-1903, tomo II, Cortes de Soria 1380.

d'Avray, David L.The preaching of the friars. Sermons diffused from Paris before 1300 (Oxford, 1985).

Deyermond, Alan D. "The Sermon and its uses in Medieval Castilian Literature", La Corónica, VIII (1979-1980), pp. 127-148;

Franco Silva, Alfonso. "El Arzobispo de Sevilla Alonso de Fonseca el Viejo. Notas sobre su vida", Boletín de la Real Academia de la Historia, tomo 196, Cuaderno 1, 1999, págs. 43-92.

García de la Borbolla, Ángeles. "Algunas consideraciones sobre la predicación medieval a partir de la hagiografía mendicante", Erebea. Revista de Humanidades y Ciencias Sociales, Núm. 1 (2011), pp. 57-82. 
García Martínez, Antonio María Claret. Los caminos de la predicación de San Vicente Ferrer. Trabajo de Investigación de Tercer Ciclo, Sevilla, 1994, inédito.

—. "El acoso a las comunidades judías en los milagros bajomedievales", La Península Ibérica en la Era de los Descubrimientos (1391-1492), Sevilla, 1997, vol. I, pp. 301-319.

- La escritura transformada: oralidad y cultura escrita en la predicación de los siglos XV al XVII. Huelva, 2006.

González Jiménez, Manuel. El Concejo de Carmona a fines de la Edad Media (1464-1523). Sevilla, 1973.

- "Nivel Moral del Clero Sevillano a fines del s. XIV", Archivo Hispalense, n. 183, 1977, pp. 199-204.

- Catálogo de la Documentación Medieval del Archivo Municipal de Carmona. (1475-1504). Sevilla, 1981.

González Jiménez Manuel; y García Fernández, Manuel (Eds.). Actas Capitulares de Morón de la Frontera (1402-1426). Sevilla, 1992.

Graña Cid, María del Mar. "Frailes, Predicación y Caminos en Madrid. Un Modelo para Estudiar la Itinerancia Mendicante en la Edad Media", Caminos y Caminantes por las Tierras del Madrid Medieval. Madrid, 1993, pp. 281-321.

Hernández, Ramón. “Actas de la Congregación de la Reforma de la Provincia de España (II)", Archivo Dominicano, II, 1981, pp. 19 y 102-103.

—. "Actas de los Capítulos Provinciales de la Provincia de España (I)", Archivo Dominicano, III, 1982, pp. 13-84, p. 73.

- "Pergaminos de la Actas de los Capítulos Provinciales del Siglo XIII de la Provincia de España", Archivo Dominicano, IV, 1983, pp. 5-73.

-. "Actas de los Capítulos Provinciales de la Provincia de España del siglo XVI (II)", Archivo Dominicano, 1986, t. VII, pp. 5-47, p. 41.

-. "Actas de los Capítulos Provinciales de la Provincia de España del siglo XVI (III)", Archivo Dominicano, 1988, t. IX, pp. 5-53, p. 46.

- . "La Reforma Dominicana entre los Concilios de Constanza y Basilea", Arquivo Histórico Dominicano Portugués, Actas do III Encontro sobre História Dominicana, Porto, 1989, vol. IV/2, pp. 151-179.

Herrera, Joseph de. Cathálogo de los Priores de el Real Convento de San Pablo de Sevilla i de los Sucesos más Notables que Acontecieron en su Tiempo. Ms. depositado en el Archivo General de la Orden de Predicadores (AGOP), Santa Sabina, Roma. Secc. XI, doc. n. 12460, n. 5.

Huerga, Álvaro. Escalaceli. Madrid, 1981.

Ladero Quesada, Miguel Ángel. Andalucía en el Siglo XV. Estudios de Historia Política. Madrid,1973, p. 116.

—. Las fiestas en la cultura medieval. Barcelona, 2004.

Longere, Jean. La Prédication Médiévale. París, 1983, pp. 93-129,

López, Atanasio. "El Franciscanismo en España durante los Pontificados de Calixto

III, Pío II y Paulo III a la luz de los Documentos Vaticanos", Archivo Ibero-Americano, 3, 1943, pp. 496-570. 
Mainardi, Hyeronimus (Ed.). Bullarium Ordine Praedicatorum (BOP). Roma 1730-1740.

Marcotegui Barber, Beatriz. "Instructio fidei. La enseñanza doctrinal en los sermones medievales navarros", Erebea. Revista de Humanidades y Ciencias Sociales 1 (2011), pp. 157-176.

Martin, Hervé. Les Ordre Mendiants en Bretagne. (Vers 1230-vers 1530). París, 1975.

—. Le Métier de Prédicateur à la fin du Moyen Age. 1350-1520. París, 1988, pp. 131-189.

Martínez Carrillo, María de los Llanos. "La crisis judaica de 1411. Aportaciones a la predicación murciana de San Vicente Ferrer", Scripta. Estudios en homenaje a Élida García García, Oviedo, vol. 1, 1998, pp. 343-365.

Merita y Llacer, Tomás. Vida, milagros y doctrina del valenciano apóstol de Europa San Vicente Ferrer. Valencia, Salvador Faulí, 1798.

Miura Andrades, José María. Frailes, monjas y conventos. Las órdenes mendicantes y la sociedad sevillana bajomedieval. Sevilla, 1998.

—. "Hechos extraordinarios y maravillosos en la Écija de fines de la Edad Media", Actas de las XI Jornadas de Protección del Patrimonio Histórico de Écija. "Acontecimientos naturales y sobrenaturales en la ciudad de Écija”, Martín Pradas, Antonio y Carrasco Gómez, Inmaculada (Dirs.). Écija, 2014, pp. 15-32.

Moliner, José María. Espiritualidad Medieval: Los Mendicantes. Burgos, 1974.

Muessig, Carolyn. "Sermon, Preacher and Society in the Middle Ages", Journal of Medieval History 28 (2002), pp. 73-91.

Muñoz, Agustín. Los Fechos de Cabildo, / (Memorias Xerezanas del Siglo XV) / Transcripción / Paleográfica de las Actas Capitulares / de 1409 a 1498 / custodiadas en el Archivo Municipal / de la M.N. y M.L. Ciudad / de / Xerez de la Frontera / por Agustín Muñoz y Gómez, / Oficial Archivero / del Excmo. Ayuntamiento de la misma / Tomo $1^{\circ}$ / Años de 1409 y 1410. I Año de 1889.

Núñez Beltrán, Miguel Ángel. La oratoria sagrada de la época del barroco: doctrina, cultura y actitud ante la vida desde los sermones sevillanos del siglo XVII. Sevilla, 2000.

Ortiz de Zúñiga, Diego. Anales Eclesiásticos y Seculares de la Muy Noble y Muy Leal Ciudad de Sevilla.... Reproducción fotoestática de la reimpresión de 1795, Sevilla, Guadalquivir ediciones, 1988.

Palencia, Alonso de. Crónica de Enrique IV. Madrid, 1904, t. I, p. 534.

Palenzuela Domínguez, Natalia. Las Actas Capitulares del Concejo de Sevilla (1435-1447). Memoria de licenciatura inédita, Sevilla, 1986.

Passio Sanctorum Martyrum fratrum Beraldi, Petri, Adiusti, Accursii, Othonis in Marochio Martyrizatorum. Analecta Franciscana, III, Ad Claras Aquas, Roma, 1897.

Pazos, Manuel R. "Los Franciscanos Españoles en el Pontificado de Sixto IV (1471-1484)", Archivo Ibero-Americano, tomo X, 1950, pp. 67-150. 
Pérez-Embid Wamba, Javier. "Sobre el trasfondo social de la predicación mendicante en Castilla y León (siglo XIII)", Erebea. Revista de Humanidades y Ciencias Sociales 1 (2011), pp. 103-136.

Pou y Martí, José María. Bullarium Franciscanum contines constitutiones, epistolas, diplomata Romani Pontificis Sixti IV, ad tres Ordines S.P.N. Francisci spectantia. Nova Serie. Tomus III (1471-1484). Quaracchi, prope Florentiam, 1949.

Rico, Francisco. Predicación y literatura en la España medieval. Cádiz, 1977.

Roa, Martín de. Écija, sus Santos, su Antigüedad Eclesiástica i Seglar. Sevilla, 1629. Reedición de 1890.

Romero Abao, Antonio del Rocío. "Las Fiestas de Sevilla en el siglo XV", CEIRA, 2. Las Fiesta de Sevilla en el siglo XV. Otros Estudios. Madrid, 1991, p. 12-178.

Rubio, Germán. La Custodia de Sevilla. Ensayo Histórico sobre sus orígenes, progresos y vicisitudes (1220-1499). Sevilla, 1953.

Rucquoi, Adeline. Valladolid en la Edad Media. El Mundo Abreviado. II. Valladolid, 1987, p. 373.

Salvador Miguel, Nicasio. "Ediciones de textos medievales, II", Medievalismo. Boletín de la Sociedad Española de Estudios Medievales, 5 (1995), pp. 263-267.

Sánchez Gordillo, Alonso. Religiosas Estaciones que frecuenta la Religiosidad Sevillana. Sevilla, 1982.

Sánchez Herrero, José. "El largo mantenimiento de unas Reformas Religiosas. 1433-1474", Historia de la Iglesia de Sevilla. Sevilla, 1992, pp. 243-299.

Sánchez Herrero, José; y García Martínez, Antonio María Claret. “Incunables de sermones de la Biblioteca Universitaria de Sevilla. Catalogación y aproximación a su estudio", De libros y bibliotecas. Homenaje a Rocío Caracuel. Sevi1la, 1995, pp. 333-352.

Sánchez Sánchez, Manuel Ambrosio. "Dos décadas de estudios sobre predicación en la España medieval", Erebea, Revista de Humanidades y Ciencias Sociales 1 (2011), pp. 3-20.

—. La primitiva predicación hispánica medieval: tres estudios. Salamanca, 2000.

Sanz. María José; y Simó, María Isabel. Catálogo de Documentos contenidos en los libros del Cabildo del Concejo de Sevilla. Sevilla, 1975, n. 308.

Sancho de Sopranis, Hipólito. "San Francisco el Real de Jerez en el Siglo XV", Archivo Ibero-Americano, octubre, 1945, n. 5, pp. 366-404 y 481-527.

Sancho de Sopranis, Hipólito. "San Francisco el Real de Jerez en el Siglo XV".

Thompson, Augustine. Revival Preachers and Politics in Thirteenth-Century Italy. The Great Devotion of 1233. Oxford, 1992.

Valera, Diego de. Memorial de Diversas Hazañas. Biblioteca de Autores Españoles, t. XX, p. 38, cap. XXXIV.

Fecha de recepción del artículo: octubre de 2015

Fecha de aceptación y versión final: noviembre de 2015 
